
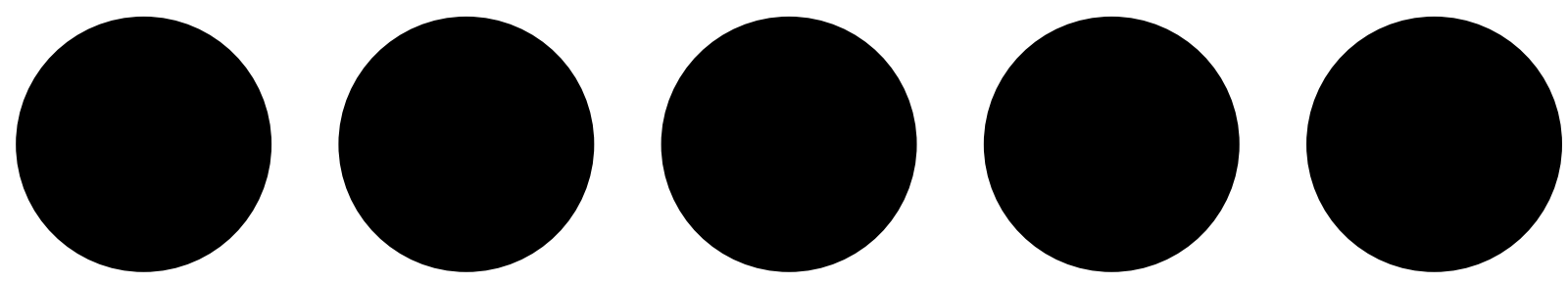

\title{
Healthy Diets from \\ a Sustainable Food \\ Production System
}




\section{Table of contents}

Executive summary

$\bullet \circ 000$

$\bullet \bullet \circ ० \circ$

$\bullet \bullet \bullet \circ$

$\bullet \bullet \bullet \bullet \circ$

$\bullet \bullet \bullet \bullet \bullet$

Analysis of the swiss
on the food system

Conclusive statements and recommendation

Glossary

Bibliography

Annexes 


\section{Executive summary} Against a backdrop of climate change and the growtions between diet, health and environment were extensively explored within the scope of National Research Programme 69 (NRP 69). Despite some remaining gap in terms of qualifying and quantifying these interactions, the knowledge currently available is abundan enough for decision-makers to plan a healthy and sustainable food system for the future.

Until 2050, the world's population is likely to reach ten billion. Providing food for so many people in a sustainato double the production of foodstuffs. They will have to do so despite the impact of climate change on essential resources such as water, soil and energy. In this context, a specific feature of Switzerland is its limited agrcultural surface area: about one quarter of the land is designated as agricultural land, and $12 \%$ as alpine agplies that a large share (50\%) of the food needs to be

Another aspect is the high prevalence of chronic diseases (mainly cardiovascular disease and cancer), many thought to be diet-related. Public health strategies tend to optimise food intake based on biomedical knowledge. In this sense, there is a growing trend to see the food system as a health provider, and not only as a food provider.

Based on the results of over twenty research groups, tions. The principal recommendation is to elaborate a Swiss food strategy, i.e. a strategy that ensures healthy and sustainable diet for the entire population. Developing a Swiss food strategy will require a concerted and coordinated effort in the public health, agriculture, agri-food-industry and environmental domains. According to an analysis conducted as part of NRP 69 , existing food safety and public health policies pursue essentially coherent goals. However, there are various

A Swiss food strategy will also consider diet in the contake into account the fact that currently two thirds of the Swiss environmental footprint occurs abroad. In fact, a nationwide food strategy will be an integral part of the global strategy to overcome climate change.
An important aim of the food strategy will be to define which kinds of diet we want for Switzerland for the coming 30 years. This is a complex issue because human diet is both a consequence and a determinant of the environmental changes.

Another function of the food strategy will be to promote academic research on the interactions between diet, health and environment. NRP 69 showed that, despite the vironment in Sitzerlond only a few groups are and on cross-sectional aspects of the food system. Moreover new avenues of cooperation between the pri and academic research institutions are needed.

Strengthening partnerships between producers and consumers was identified as an emerging trend. NRP 69 also recommends taking various measures to increase consumers' influence on nutrition-related decisions, inand giving consumers the right to file class actions.

Modelling the current and future food systems can greatly help to understand their functioning. According to the available literature as well as the models generated in NRP 69, reducing meat consumption is probably the single most important diet-related factor in transitioning to a healthier and at the same time more sustainable food system. These models also show that it is not possible to achieve healthier diets and sustainable health, protecting the environment and manaproving production need to be integrated into a systemic framework and, ultimately, a common strategy.

The different projects selected and funded by NRP 69 have presented specific recommendations. To foster healthy and sustainable eating, public bodies should increase awareness nationwide regarding the benefits of diets consisting of more fruits and vegetables and less meat. NRP 69 shows that, fortunately, diets preventing for the environment. Incentives such as lower pricing should be devised to encourage consumers' to choose healthier foods. Moreover, the workplace provides good setting to promote healthy eating. A new tool has been developed to monitor caloric intake, which could help people lose weight. Deficiency-related diseases are a classic theme of nutritional medicine. New approaches have been proposed, for example developing new di- 

Enhancing sustainability in the Swiss food system will
have to be approached from different angles. These include increased environmental performance by dairy farms, including the reduction of particulate matter, protecting the environment of animals, or limiting metal pollution in the soil. The drive to increase the effectiveness of food production can also benefit from new information for better crop rotation to avoid fungal infection. The reduction of food losses and waste is another imsystem. Several projects proposed new ideas and new tools on this topicojects proposed new ideas and new

in the other National Research Programmes, the topics addressed by NRP 69 were defined by the Federal Council. The programme was managed by the Swis National Science Foundation. The main objec these programmes is to address current and future socio-economic issues of national importance. 
Scope and structure

Since 2013, 26 research groups involved in national research programme "Healthy nutrition and sustainable food production" [NRP 69] realised studies on promoting healthy eating from sustainable food production in Switzerland. This chapter describes some of the characteristics of the swiss food system and explains the challenges it faces. It also outlines the scope and structure of NRP 69 within this context.
of National Research Programme 69
"Healthy nutrition
and sustainable food production"

The 8.4 million consumers in Switzerland are at the end of the supply chain for foodstuffs ${ }^{1}$. Current thinking and policies tend to replace "consumers" with "healthy consumers", in part reflecting changes in policy priorities from food (and calorific) availability to healthy food consumption practices ${ }^{2}$. This reflects an evolution which considers the food system as a health provider, and not as a food provider only. Further, because of the substantial impact of the food system on the environment

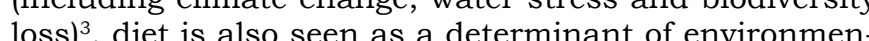
tal sustainability.

In 2016, the proportion of food consumption (in terms of usable energy) covered by Swiss domestic production was $56 \% \%^{4}$. The value of the food imported from outside Switzerland amounted to CHF 12 billion. Imports are consequence of the geographical and natural limits of Swiss agriculture and the globalisation of the food trade and contribute to dietary diversity through the year. country, Switzerland is dependent on the global food market to a large extent.

The Confederation's outlays for food production in 2018 represented $5.2 \%$ of the total federal budget. This included social measures, administration, implementation and monitoring expenses, improving the production base, production and sales and direct payments ${ }^{4}$. This support is "intended to ensure that through sustainable and market-oriented production, agriculture can make a conserving natural resources, preserving the countryside, allowing decentralised land settlement and ensuring animal welfare"4. This means that the Swiss food system is shaped by a system of tariffs and public funding from the federal state.

Why should we bother now?

The world's population (about 7.7 billion today) is currently increasing and will continue to do so until 2050 . manner is no easy challenge 5 . By 2050 , farmers are expected to double the production of foodstuffs. They will have to do so in a context in which the consequences of climate change are expected to impact many regions of the world, affecting water, soil and energy resources, all of which are relevant for food production ${ }^{6}$. 
Although there are gaps in the quantification of the interactions between climate change, public health and recognise that policymakers need to act now to ensure a healthy and sustainable food supply in the future.

Western Europe has not been visited by famine for the past 70 years (since the end of World War II). At a globa
level, up to one billion people lack food security

There are three problems ahead, one related to the quantity of foodstuffs, the other to their quality and a is an obvious response to increased global demand. However, such an increase in food production would im pact the environment by, e.g., accelerating biodiversity loss, water scarcity, land degradation, climate change and nutrient oversupply. Therefore, innovative solution are required to feed the future population without an

There are strong arguments in favour of eating less animal-derived food. One is the high environmental impact of meat consumption ${ }^{8}$. A second argument is the growing concern about animal welfare under industrial farming conditions. Finally, reduction of the consumption of red meat, and notably, processed meat, could also be beneficial for health ${ }^{\text {. }}$

New kinds of food are being developed, containing for example insects as protein providers. Moreover, food ready on the market, e. tofu, tempeh, seitan or other meat analogues.

Another response to the increased demand for food is to limit losses and waste. About 33\% of the edible food mass is lost or wasted at a global level ${ }^{\circ}$. In Switzerland, a total of 2.6 million tonnes of food waste is generated annually. Therefore, appropriate tools combining incentives and penalties

As for food quality, the dietary diversity is probably the single most important protective food-related factor of human health in Western Europe ${ }^{12}$. This diversity accounts for much of the historical improvement in health status in Western Europe. However, diversity has an environmental cost, e.g. because it depends on imports and/or may come from non-seasonal production.

A lot was expected of vitamins and other micronutrien A lot was tury. Several diseases were found to be linked to specific protective or toxic agents. Correcting these anomalies was effective in controlling or eliminating these diseases (e.g. iodine against goitre and cretinism, vitamin B3 against pellagra, vitamin $C$ against scurvy, etc.). However, the interaction between diet and health is much more complex in most other cases: only a very to a single, specific substance that can be added or removed from an ordinary diet.

Food production is increasingly considered in a broader context: the environmental impact of the food system has become important and concerns about climate change and biodiversity loss have brought food production into focus. Food production is perceived as both a consequence and a cause of environmental issues It contributes to climate change (e.g. by increasing aremissions from livestock farming); at the same time the changing climate impacts the volume and nature of food production (e.g. by reducing biodiversity).

Due to the increased pressures of climate change and biodiversity loss, there is strong public concern for the health of the planet and the future of humankind.

NRP 69: three key questions

The National Research Programme (NRP) 69 was launched in 2011 to explore these interlinkages and fin for healthy nutrition in a Swiss context.

National Research Programmes (NRPs) are an established way of addressing new issues and exploring possible responses to socio-economic problems of national importance. NRPs are expected to genlerate scientific knowledge aimed at solving Switzerland's most pressing problems are managed by the Swiss National Science Foundation.

A new series of NRPs is launched periodically, with budgets ranging from CHF 15 to 30 million. The maximal duration is 9 years (with 5 years devoted to research). In every NRP, 20-50 coordinated projects ar generally funded for research periods of 3-4 years. 
NRPs are characterised by problem-solving approaches, inter- and transdisciplinarity, coordination of single propublication and implementation of the results, and dialogue with the target groups.

NRP 69 was launched in March 2011 by the SNSF under a mandate from the Federal Council. In Summer 2011, international ad hoc experts were invited to deprogramme proposals submitted to the State Secretariat for Education, Research and Innovation (SERI) by researchers and federal offices. In March 2012, the Implementation Plan was approved by the Head of the Federal Department for Home Affairs.

The Steering Committee members were elected and the call for proposals was open from February to April 2012

The programme included interactions with the Commission for Innovation and Technology (KTI Innosuisse - and the Joint Programming Initiative "A Healthy Diet for a Healthy Life" (JPI-HDHL).

The goal of the programme at research level was to provide answers to three key questions:

How can healthy eating be encouraged in

How can a sufficient supply of safe food products be made available at affordable prices?

How can the production, processing and distribution of food be managed efficiently with the least impact on the environment?

The two following chapters, 2 and 3, provide some answers to these questions based on the results obtained in NRP 69 research projects. Chapter 4 subsequently sectors a griculture, food safety and public health key conclusions and recommendations drawn from NRP 69 are outlined in the final chapter. 


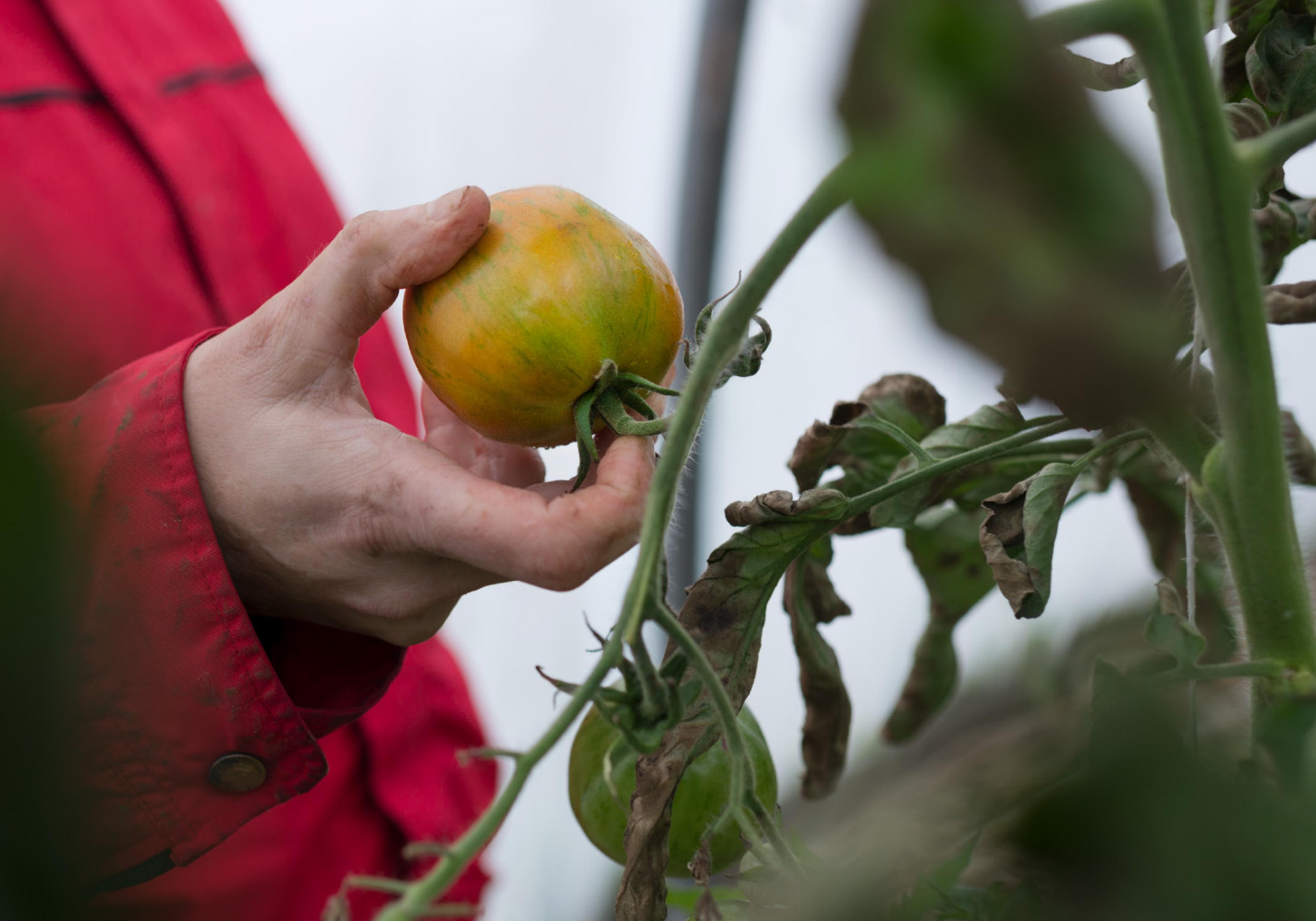


As part of the National Research Programme 69, researchers took a close look at the Swiss population's eating habits. A healthy and sustainable diet means eating more fruits and vegetables section summarises the results of the NRP 69 projects on healthy and sustainable nutrition.

Fostering healthy and sustainable eating

\section{Context}

Comparisons between current Swiss diets and optimal diets show that many people in Switzerland still eat unhealthily and/or unsustainably, even though health literacy in Switzerland is on average high: most of the population can distinguish healthy from unhealthy and sustainable from unsustainable foods. Such discrepancies are often found in the environmental domain and in the public health sector: consumers do not necessarily act according to their knowledge. We therefore have to accept that knowledge has a limited impact on we

There are various reasons why individuals opt to eat unhealthily and/or unsustainably. Some don't have enough time to prepare proper meals, others buy the cheapest food they can find. Cravings, enjoyment and rewards also play an important role. People with an unhealthy diet are more likely to be overweight or to suffer from conditions such as diabetes, cardiovascular disease or cancer. The direct and indirect health costs of an unbalanced diet tripled in Switzerlan between 2002 and 2012 to eight billion francs a year ${ }^{13}$.

Dietary patterns also directly influence the environment. According to research the environmental and climate impact of food consumption in Switzerland a 


\section{The health costs of an unbalanced diet}

The direct and indirect health costs of an unbalanced diet tripled in Switzerland between 2002 and 2012.

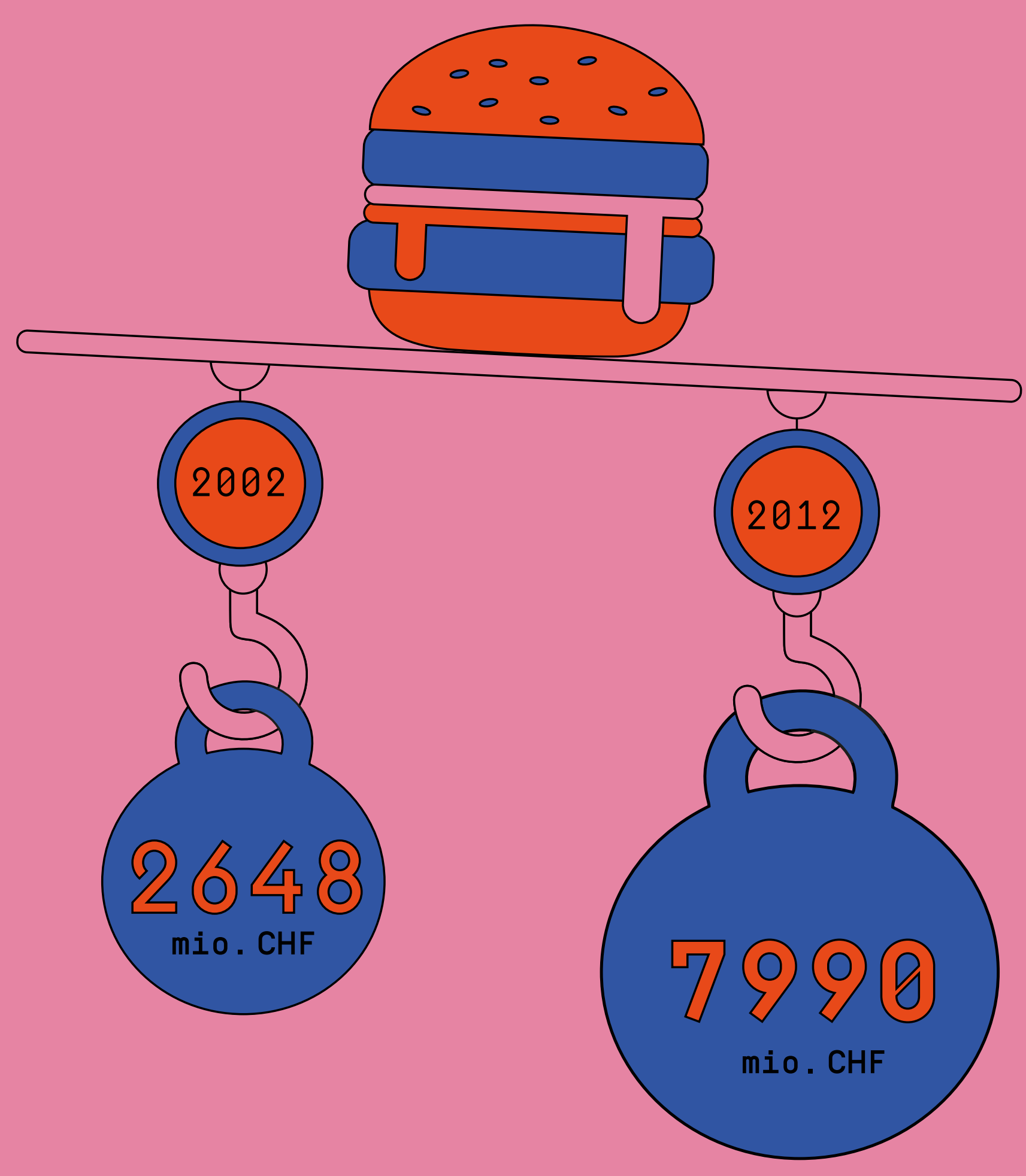

More fruits and vegetables, less meat

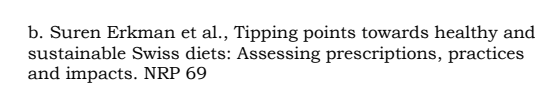

b. rbid

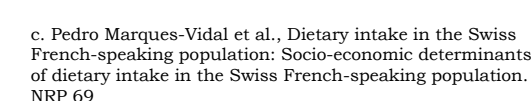

Making healthy food cheaper

c. Ibid.

Encouraging healthy eating in the workplace
The project "Toward healthy and sustainable diets in a close look at the Swiss population's eating habits.

On average, men eat more meat than women do. Furthermore, people in French-speaking Switzerland and Ticino tend to eat less healthily than people in the German-speaking parts of the country, although eating in overall terms between 1993 and 2014c. One characteristic of the Swiss population is that there
is a less significant divide between the dietary habits of people from different socio-economic groups than in other countries. In general, the inhabitants of Switzerland should eat more fruit, vegetables, wholegrain foods, nuts and pulses, while consuming less animal products such as red and processed meat.

The project "Social inequality" investigated the eating habits of people living in Western Switzerland and ide. Survey still view high food prices as an obstacle to healthy diet.

Other reasons for not adopting a healthy dietary profile were frequently cited, including a fondness for indulgen

Because it is difficult to change the many personal reasons that motivate eating habits, the researchers of the "Social inequality" project" suggest selecting extensive measures that do not focus on specific population groups. They recommend reducing the price of healthy foodstuffs, particularly fruits and vegetables, for example by fostering domestic production. Of the Swiss working population, approximately one
million eat in a staff restaurant or canteen during the week ${ }^{14}$. Organisations with catering facilities therefore have considerable influence on the health of a large portion of the country's population.

Two NRP 69 projects have developed various ideas that companies could apply to encourage healthier food in take anong their stafr. Their results could help us move a step closer to the goal of ensuring that people eat action plan for the Swiss Nutrition Strategy. 
The "Salt consumption" project explored ways of encouraging the Swiss population to take up a balanced, less salty diet. Nowadays people's salt intake largely
exceeds the five grammes a day recommended by the World Health Organization.

The researchers studied seven different organisation with staff restaurants in German-speaking Switzerland using a two-sided approach. On the one hand, they sensitised employees of the organisations to the issue followed up with quarterly health checks. On the other hand, they assisted catering teams in planning and implementing measures to reduce the salt content of the meals they usually provide.

Although the standard plated menus contained almost as much salt at the end of the one-year intervention as initially measured (median salt content 4.4 instead of 4.5 grammes per serving), average salt intake of in day. While women's mean daily salt intake remained unchanged at 7 grammes - that is already below the intermediate Swiss salt intake target - men's fell from 10.4 to 9.2 grammes a day. In general, salt reduction was stronger at higher initial values. In women, age and weight played a role in reducing the amount of salt. programme, developing a stronger awareness of health and nutrition during the year.

The research results show that - given a supportive food environment - regular practice-oriented educational
workshops can initiate health relevant changes of dietary habits. Therefore, the researchers recommend systematically extending workplace health promotion to include nutrition. They suggest that guideline values for salt content should be included in existing staff restaurants' health label criteria. Another project that addressed the issue of nutrition in the workplace was "Health motivators"e. Researchers
working on the project investigated how environmental stimuli affect our eating habits. They positioned posters showing different subjects - for example, photos of sculptures by Alberto Giacometti or pleasure-evoking pictures of a funfair - next to vending machines, then evaluated the posters effect on consumers choices. While pictures of landscapes or activities did not affect he quantity of food purchased, they increased th

However, a poster of a skinny Giacometti sculpture next to a vending machine had the effect of reigning in neople's appetite. They ate less than if they had used a machine with no poster or a machine with funfair images. This led the researchers to conclude that environmenta stimuli can activate health motivators. The researchers believe that the use of nutrition-related stimuli does not
Helping with weight loss

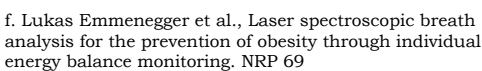

g. Peter Fischer et al., in
Emulsion Systems. NRP 69 69

W approaches to

cy-related

diseases
Two further projects from NRP 69 produced results that could help people lose weight.

Researchers working on the "Preventing obesity" project developed an instrument that uses a breath sample to determine whether the body is metabolising fat at the moment the measurement is taken. The device uses laser spectrometry to measure the concentration of acethis volatile organic compound when it is using modes

The tests indicate that acetone content in breath is a promising biomarker for measuring the energy balance the energy deficit.

Such measuring instruments could therefore help obese patients to monitor their efforts to lose weight and motivate them to continue. This is in line with the current markers for the quantitative follow-up of exposure or of the disease.

Further development is necessary to reduce the instrument's size and to enable simple practical application.

In the second project - "Functional food" bound fat droplets into emulsions that release triglycerides only in the duodenum and investigated whether the ing satiation after eating. Their investigations reveloa that the emulsions do trigger the satiation stimulus in both animals and humans. This indicates that the special emulsions are suitable for controlling overweight people's energy intake more effectively. However, the researchers point out that widespread use (in salad dressings, for example) will not be possible without improve-
ment of the sensory characteristics of the emulsions.

But NRP 69 did not only address nutritional excesses and how to avoid them. It also looked at the opposite end of the spectrum and ways of avoiding shortfalls in vitamin and mineral intake.

More than two billion people worldwide - primarily women and children - suffer from iron deficiency ${ }^{15}{ }^{1}$. The condition causes various problems, including reduced performance, anaemia and a greater susceptibility to diseases. Food supplements aurrently on the market do ther hard to digest or have a detrimental impact on the flavour, odour or colour of food. 

adding the trace elgood bioavailability and do not affect taste, they do frequently oxidise and form aggregates, so that the body can no longer utilise them.

The researchers have developed a hybrid material that stabilises the iron nanoparticles. The nanoparticles adof the edible milk protein beta lactoglobulin, a by-product of cheese production. In tests on rats, the researchers established that the iron nanoparticles do not re-dissolve until they enter the acidic environment of the stomach, after which they are rapidly absorbed by the body.

Because the new hybrid material is not only taste-neutral but has a long shelf life and is cheap to produce, the researchers feel that their invention has significan potential as a way of combating iron deficiency - espeis particularly widespread.

The research group conducting the "Dietary fibre" project analysed the chemical properties of beta-glucan in cereals. This dietary fibre helps to reduce the blood cholesterol level and to control blood sugar. The researchers analysed the effects of food processing on beta-glucan as well as on sever -glucan.

The project increased our understanding about the beneficial effects of beta-glucan on health, owing to its interactions with iron and mucin, for example. The researchers call on decision-makers and practitioners to invest more effort in encouraging consumers to gain a better understanding of the components of food. They also invite industry to apply the knowledge gained from the work on this dietary fibre to produce tailor-made foods for individobesity.

The "Vitamin D"j project investigated the vitamin D status of expectant mothers in Switzerland and found that more than half of the pregnant women had too little vitamin D in their blood. The lack of vitamin D during pregnancy is the most important determinant factor for atal growth ${ }^{16}$

The median level of vitamin $\mathrm{D}$ in the blood was higher in summer than in winter. Women from Ticino - the sunniest part of the country - had a lower risk of deWomen witamin $\mathrm{D}$ deficiency than women from Zurich. low vitamin D levels.
The researchers conclude that Swiss guidelines on vitamin supplementation as they currently stand do not adequately protect pregnant women against vitamin $\mathrm{D}$ de-
ficiency, either because the recommended doses are to low or, more likely, women do not take their supplements regularly. Medical practitioners need to pay greater attention to vitamin $\mathrm{D}$ supplementation during pregnancy.

\section{roundwork for a healthy} The Swiss population's eating habits have far-reaching consequences. The way that food is produced, processed
and consumed not only influences human health, it also has repercussions for the environment, the econom and society as a whole ${ }^{17}$. Researchers working on the "Recommendations for sustainable and healthy diets" project $^{k}$ modelled various future scenarios in a bid to assess these impacts with greater accuracy. The mod els show that reducing meat consumption would lead to people follown a healthier diet and a food producsustainable.

The first scenario assumes that in 2050 the Swiss population will be following the recommendations of the Swiss food pyramid. By contrast, the second scenario, "FeedNoFood", envisages eating habits that are primarily driven by environmental awareness. This scenario assumes that in 2050 livestock in Switzerland will have a diet consisting entirely of grass and food processing duction of animal feed and of human food are in competition, will have ceased to exist. Both, the pyramid and the "FeedNoFood" scenarios, are based on the assumption that the Swiss population will be eating less meat and more pulses by 2050. The third scenario envisages no change in the country's eating habits.

The analysis showed that the two alternative futur scenarios basically imply similar adjustments in eating habits. In both cases, meat consumption is significantgenerates positive synergies between sustainability and public health: a diet with less meat is healthier and at the same time improves the ecological and social sustainability of food production.

In addition, the analysis suggested that the net self-su ficiency of the Swiss food sector is likely to increase as a result of falling imports of fodder for meat production, and consumers food expenditure will decrease as their the mare on expenel, howel pr, such a change w. At result in lower added value for the Swiss food sector. 


\section{The Swiss \\ food pyramid}

However, the analysis of the scenarios also showed that a change in eating habits leads to many contradictions. There are substantial contradictions in current dietary pact models. For example, meat should be eaten as a source of minerals, protein and vitamins, but epidemiological studies suggest that small increases in the risk of several cancers may be associated with high consumption of red meat or processed meat. Another contradic products such as pulses need to be imported, we have to consider the social impacts in exporting countries. These need to be resolved in order to reduce confusion among consumers.

Another conflict identified in the study lies in the expansion of organic production. A higher share of organically produced food could reduce the environmental impacts in Switzerland but would - without changes in diets lead to higher inport lad

While fruits and vegetables are considered as healthy, they are quickly perishable and thus contribute to higher amounts of food waste at all supply chain levels. More efficient logistics and a better shelf life of foodstuffs could alleviate this negative impact on the environmen in the future.

These examples show how the models substantially constrictly to understanding the discrepancies between a sive food system view.

The project also showed that a healthy diet and sustainable food production cannot be achieved through unilateral action within the food system. According to the researchers, health, food and agricultural policies three areas that are currently independent of each other - need to be coordinated into a systemic and shared framework for a future Swiss food system that provides population as possible.

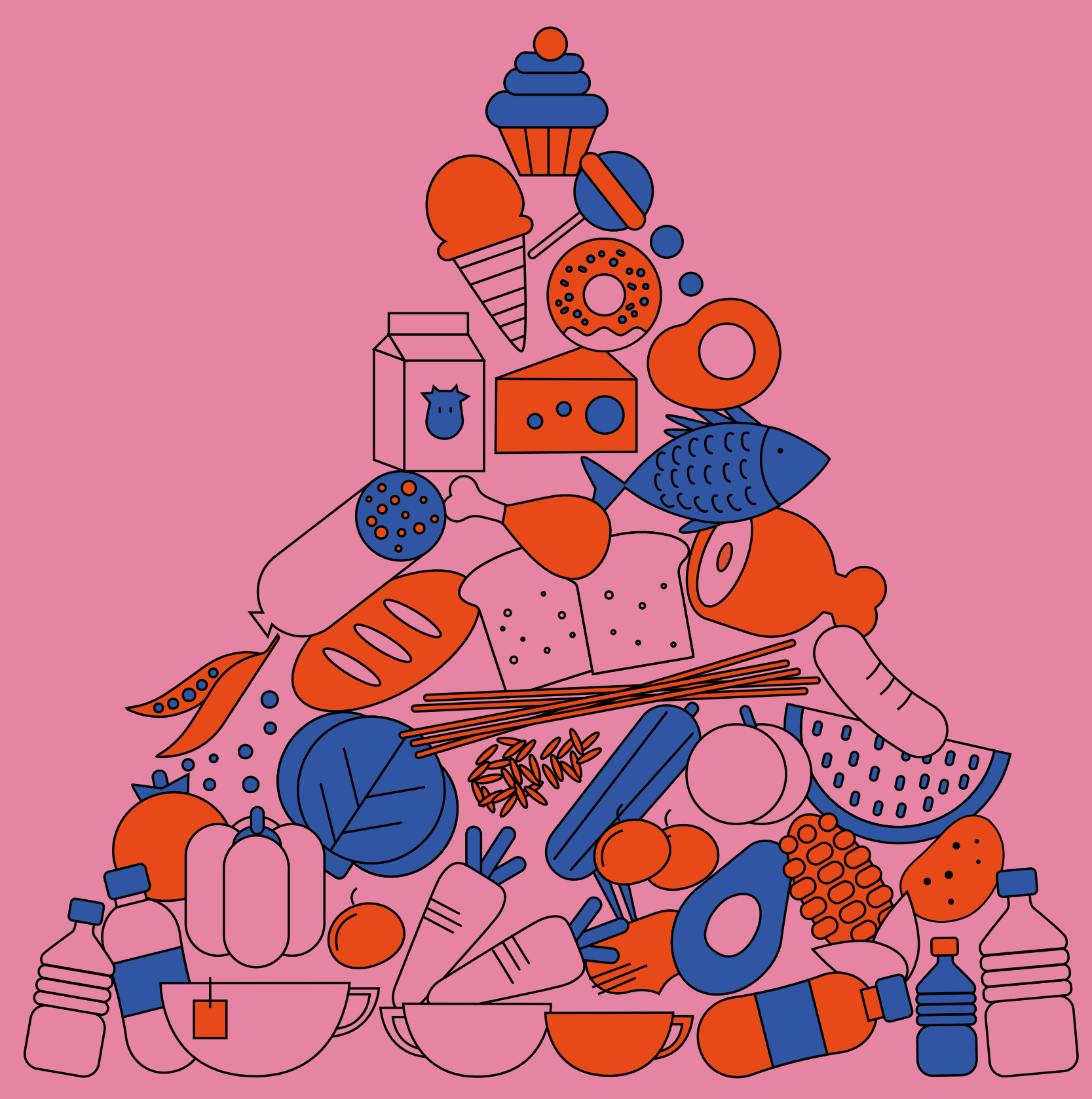




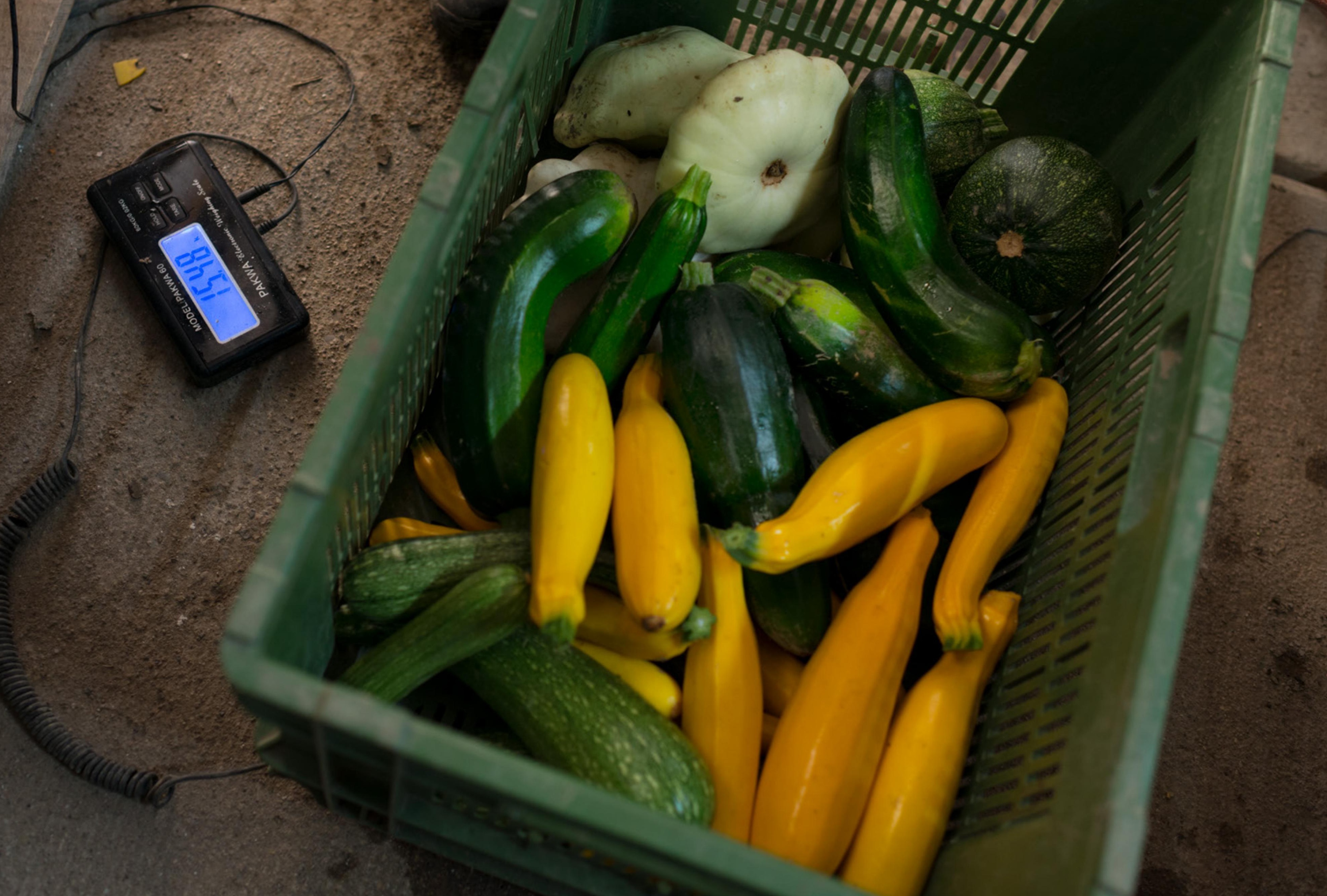




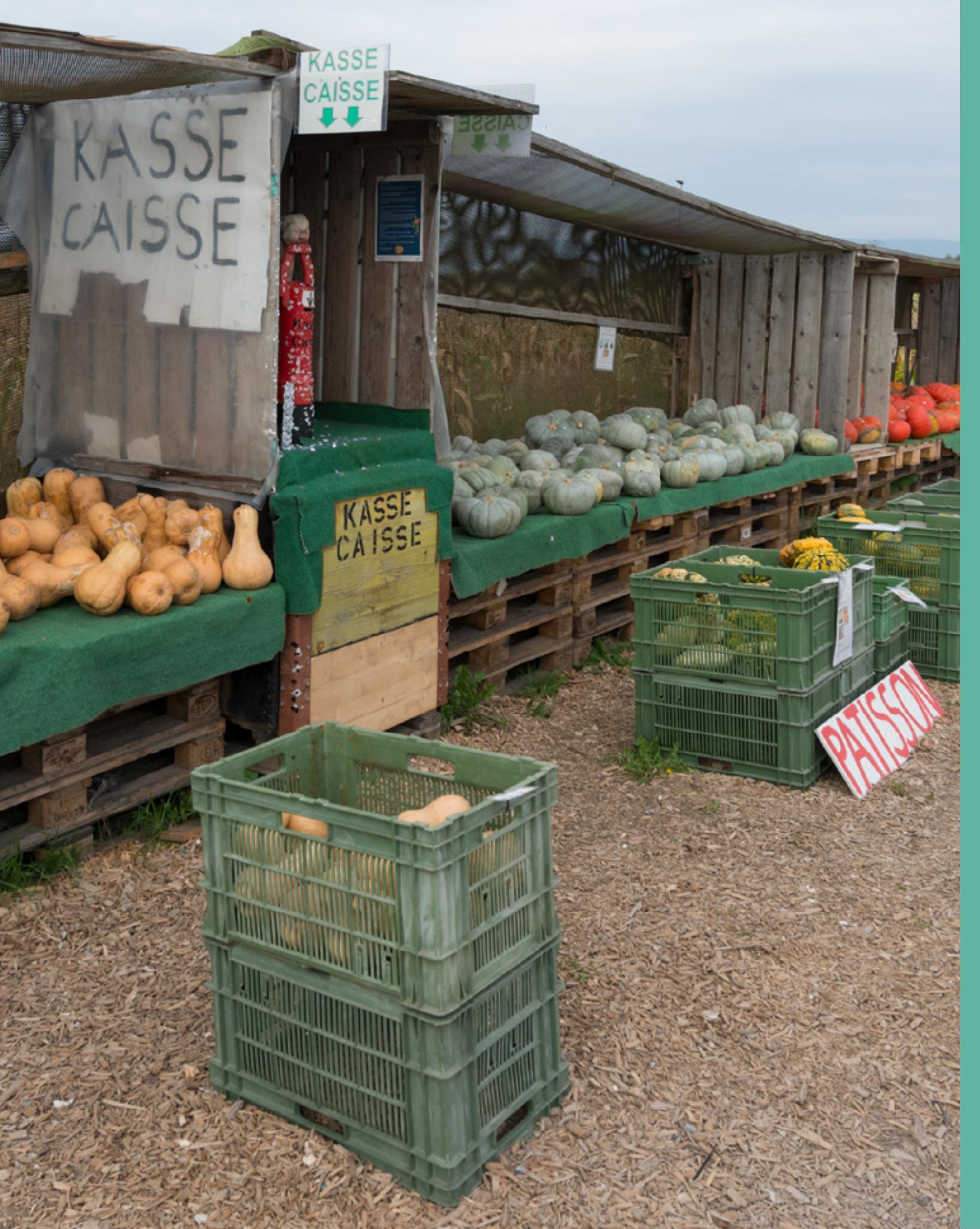



Scientists working on NRP 69 have developed various proposals
for producing meat, milk and vegetables in an environmentally friendlier way. Some of these proposals can also have direct positive effects on human health.

A more sustainable Swiss food system a. Birgit Kopainsky et al, Environmental-economic models for
evaluating the sustainability of the swiss agri-tood system. NRP 69

Environmental performance of dairy farms in Swiss

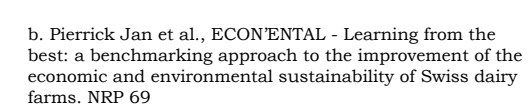

emissions in dairy housing

c. Sabine Schraded et al, Sustainable milk production
systemss ammonia and greenhouse gas emissions and
The project "Sustainable agri-food systems" found that the agri-food system is responsible for about one third of all environmental impacts in Switzerland. Given that this sector accounts for just seven per cent of the national gross added value, this means that the sector disproportionately contributes to the environmental burden. Coordination between agricultural production, the processing industry, wholesaling, retailing and the consumption or feod is noeded to make the food sys

In this chapter, "sustainability" refers mainly to the enstances also to its social and economic dimensions.

In the "Sustainable milk production" project ${ }^{\mathrm{b}}$, research ers assessed the environmental performance of dairy recommend always taking into account both the the and the global dimension when determining the environmental performance of farms, but distinguishing clearly between the two.

The research group identified factors that could potentially simultaneously improve both the global and local environmental performance as well as the economic performance of dairy farms in mountain regions. These factors are organic farming, better educated farm managers trate fed, larger fant, liw-intensity und of cattle concen-

Dairy farming accounts for a significant share of agricultural greenhouse gas and ammonia emissions. Ammonia not only harms sensitive ecosystems, it can also contibute to the formation of particulate matter that can harm human health ${ }^{18}$.

For these reasons, one of the targets in the Umweltziele Landwirtschaft $t^{18}$ is a $40 \%$ reduction in ammonia emis-
sions compared to 2005 in Switzerland. Researchers working on the "Cow emissions" ed the efficacy of various measures to reduce ammonia emissions. They found out that structural measures, which address the soiled floors, the main source of ammonia, are very promising. 

The first structural measure investigated was a floor
with a $3 \%$ slope, so that the cows' urine could drain rapidly from the floor surface to a central gutter. An automatic manure scraper ran 12 times a day to enable unhindered drainage. First results showed $20 \%$ lower
ammonia emissions in the system with the sloped floor compared to the reference system without slope.

The second structural measure which resulted in a siging stalls". The cows stood on a rioised feeding ac with partitions. Since there was hardly any faeces and urine on the platform, the heavily soiled area was reduced. The aisle behind the feeding stalls was frequently cleaned using a manure scraper without disturbing the cows while they were feeding.

In addition to the reduction of ammonia, both measures also led to cleaner and drier floor surfaces, which improved claw health and housing hygiene.

Both measures have been incorporated into the new "Ordinance on Structural Improvements in Agriculture" 19 . The Ordinance provides financial support for farmers who implement these measures to convert or build cattle housings.

Like dairy farming, meat production also has an impac on the environment. Over the past 30 years, average meat grammes a year ${ }^{20}$. Pork is still the most popular meat in the country, as the 2017 figure of 22 kilogrammes testifies. Researchers of the "Healthy pigs" project developed a model for pork production that not only reduces ammonia and greenhouse gas emissions, but simultaneously improves the animals' health and well-being.

To reduce greenhouse gas and ammonia emissions, this research group explored the pigs' protein efficiency. The the less of it ends up in slurry as a source of nitrogen and ammonia.

The researchers also conducted a study of 112 pig farms to investigate when and where infections were most frequent and antibiotic use had to be increased in response.

According to the researchers, the following factors are essential for low-antibiotic pig rearing: good trough hygiene, appropriate amounts of special feed for young an imals and avoiding that animals of different ages share contributes, among other things, to preventing the further spread of antibiotic resistance in bacteria that are pathogenic for humans and animals.

\section{imiting metal pollutio}

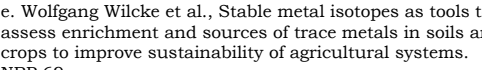
Two NRP 69 projects addressed the environmental im-
pact of arable farming. The "Metal exposure"e project investigated levels of cadmium, copper, uranium and zinc in Switzerland's arable land and grassland.

The results show that agricultural practices during the last fifty years have caused an accumulation of these metals in the soil. This is worrying for two reasons. No only can elevated metal concentrations affect soil fertili-

Over a one-year period, the research team took various soil samples from three different cornfields to which mineral fertilisers had been applied and three pastures that flow and outflow in them.

The researchers found that the four metals had accumulated in the upper soil layers of all the fields they uranium was mineral phosphate fertiliser. To limit meta pollution in the soil, the researchers recommend introducing a new uranium guidance value for mineral fertilisers and carefully checking this value and the guidance value for cadmium.

In addition, the accumulation of both metals could be avoided by increasing the use of recycled fertilisers from sewage sludge ash, provided that

Manure is the primary source of zinc and copper in the soil. Both trace metals are contained in the feed as admanure.

To reduce the input of copper and zinc in the future, the researchers recommend that the guidelines relating to the addition of copper and zinc to animal feed be strictly applied and that liquid manure distibution be optimised varieties that absorb very little cadmium but transport zinc efficiently into the grain should be encouraged.

\section{Change crop rotation to
avoid fungal infection}

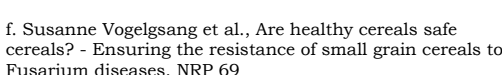

The "Safe cereals" project compared different grain varieties in terms of their resistance to Fusarium infections. The main issue addressed by the project was how to reduce Fusarium infection in cereals. Because these fung pose a heath isk if they contawn as mycotoxin

In growth chambers and field experiments, the researchers established that barley was more susceptible to Fusarium infection at $15^{\circ} \mathrm{C}$ than at cooler $\left(10^{\circ} \mathrm{C}\right)$ or warmer $\left(20^{\circ} \mathrm{C}\right)$ temperatures. Barley proved to be less resistant than oats at all stages of its growth. 
Their results confirm that modifying crop rotation is the most effective way of preventing mycopoxin contamination. Barley should not be sown in fields where maize was the previous crop, while oats should follow largegrained cereals.

Two thirds of the Swiss

g. Birgit Kopainsky e tal, Environmental-economic models
for veluating the sustainability of the Swiss agri-food
system. NRP 69

Strengthening partnerships consumersoducers and

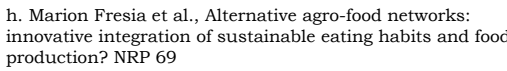
possible trends in the Swiss food system as part of NRP
69 . The researchers applied two environmental according to the ecological scarcity method, greenhouse
The "Sustainable agri-food systems" project ${ }^{g}$ simulated nomic models. One of them shows that the agri-food system in Switzerland accounts for $17 \%$ of greenhouse gas emissions.

Most of the greenhouse gases are attributable to meat and milk production. Moreover, agriculture has a heavy environmental impact because it involves considerable amounts of land and water. In contrast, the environmental impact of the food processing industry, and these sectors generate the most added value.

The research team also showed that around two thirds of the environmental footprint of Swiss food consumption occurs abroad because of the amount of food, feedstuffs and raw materials that Switzerland imports. The fact that the majority of environmental impacts occur abroad refers to the aggregated environmental impacts

Researchers from the "Organic food baskets" project argue that efforts to make food supplies in Switzerland more sustainable should involve integrated strategies that target producers and consumers. They propose standard integrated strategy.

The project shows that encouraging people to eat locally sourced, seasonal food not only supports domes-
tic producers, but also helps promote a healthy and sustainable diet Over the last thirty years, there has been a growing interest in regional food networks in Switzerland. Such networks offer regional products by subscription, creating a direct partnership between farmers and consumers that allows them to share the risks if for example, harvests are low due to bad weather.

The research group working on the "Organic food baskets" project carried out case studies on three differen schemes in French-speaking Switzerland. They found phenomenon into more rigorously structured systems. But the systems seem to be having trouble gaining the
acceptance of broad sections of the public. $80 \%$ of the members of the food networks had a high education lev$\mathrm{el}$ and belonged to the middle or upper classes.

In all three case studies, the subscription system brought producers greater autonomy because food baskets give them a more secure basis for planning. Moreover, many farmers reported that their work was consumers. Simultaneously, courages healthy and sustainable eating habits.

The researchers therefore recommend promoting LCF schemes, for example by increasing the number of partnerships between local producers and public and semistate-controlled institutions such as crèches, schools, retirement and care homes. 


\section{The environmental footprint of Swiss food consumption}

Reducing food losses and waste: a source of leverage to make the food system more efficient and sustainable

Worldwide, around one third of all the food produced for human consumpFederal Office for the Environment $(\mathrm{FOEN})^{11}$. This translates into 2.6 million tonnes a year, with two thirds avoidable. On average, every inhabitant waste 190 kilogrammes of edible food per year.

An estimated $37 \%$ of food losses occur in the industry; the catering trade accounts for $11 \%$ and the 900,000 tonnes a year - occurs in consumers' households ${ }^{1}$.

According to the Food and Agriculture Organization ${ }^{10}$, food waste refers to the discarding or alternative (non-food) use of food that is safe and nutritious for human consumption. According to the same source, food losses can be defined as the decrease in food, either in quantity or quality. These are agricultural or fish products intended for human consumption, which are ultimately not nutritional, economic value or food safety. They occur throughout the food supply chain. Knowing that two thirds of the environmental footprint of Swiss food consumption occurs abroadi the impact of food production in Switzerland is obviousty limited. Thus, systematically reducing losses and waste could help Envronmentalecenomich model for make the Swiss food system more sustainable in a relatively short time. The communication activities to raise public awareness of the issue of food losses ${ }^{11}$.

However, the Swiss government ratified the Sustainable Development Goals $(\mathrm{SDGS})^{21}$. Goal 12.3 calls for edible food waste to be halved at the retail and cessing industry by 2030. Therefore, the FOEN is developing a strategy to monitor and reduce food waste ${ }^{11}$.

As part of this strategy, the FOEN published a report summarising amounts of food waste and environmental impacts in Switzerland, in collaboration with ETH Zurich $^{11}$. The objective of this report is to identify hotspots of environmental relevance, deduce effective measures for food waste prevention, create a scientific basis for an awareness-building campaign and identify major research gaps.

of the environmental footprint of Swiss food consumption occurs abroad because feedstuffs and raw materials that Switzerland imports.
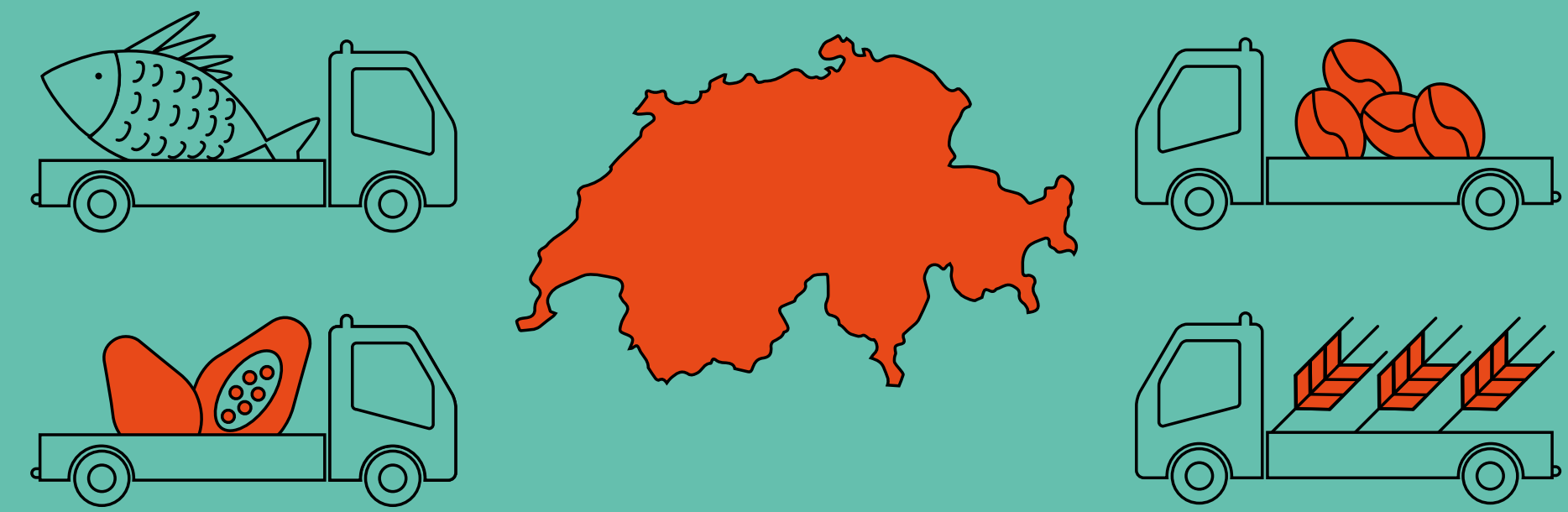

One of the problems in conducting this type of analysis is how to measure losses and waste. At European Union level, in May 2019, the European es and waste in the $\mathrm{EU}^{22}$.

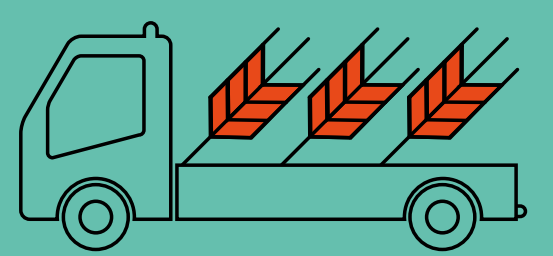


A study on potato losses

of the Swiss potato crop is not consumed by humans.

$0000 \bigcirc 000$ 000000000 0000000000 0000000000 00000000 0000000000 0000000000 $\because \because \because \because \because \cdots)$ $\because \because \because \because \because \because \cdots) \because \because \cdots)$ 0000000000

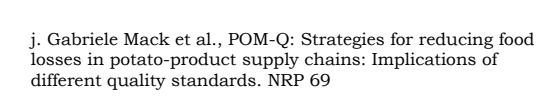

Innovations in date-marking and food preservation

k. Cornelia Palivan et al, protein
preserve food duality NRP 69

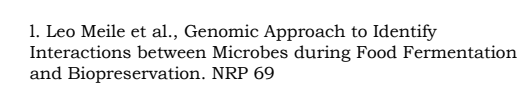

The general issue of food losses and waste and the scale losses and waste" on page 43). However, it will only be possible to efficiently reduce food losses and waste if we have detailed information at each stage of the food value chain. At present, there are few comprehensive surveys of individual foodstuffs.

In NRP 69, one such initiative was carried out along the value chain for Swiss potatoes: the "Food losses" project
showed that no less than $53 \%$ of the potato crop is not showed that no less than $53 \%$ of the potato crop is not farm-level. Having detailed insight into the potato value chain enabled the researchers to propose measures to reduce food losses and waste.

The project suggests that the cosmetic standards for potatoes be reduced, and that potatoes that do not meet the standards for food processing be used as fodder. Additionally, the team suggests that smaller, lightproo of potatoes to cover their needs.

These propositions are tailored to the potatoes value chain and cannot be easily transferred to other foods. The researchers recommend analysing the food value chain of other products, e.g. different types of vegetables, in a similar way. This will identify the extent and causes of waste at each stage of the value chain and provide a basis from which effective measures to reduce
food losses and waste could be developed.

The "Nano-preservation"k project provides a nanotechnology-based alternative to best-before dates of certain foodstuffs. The research group developed smart labels for packaging that react, e.g., to $\mathrm{pH}$ change in the food. Thus, for food that turns acid during spoilage, its deterioration is indicated by a change in colour or fluorescence of the labels. This technology is not ready yet fo the market, further research on other indicator systems, costs of such packaging is needed.

Another project called "Preservative bacteria"1 investigated the possibility of using lactic acid bacteria as a possible way of preserving food for longer. The researchers developed a process for selecting the bacterial cultures with the best preservative properties.

Using such cultures in production processes could increase food shelf-lives and food safety by reducing contaminations. This could be the case for Staphylococc stances in the food that are toxic for humans. Other examples are contaminations with Listeria or Salmonella, two widespread pathogens. The food industry is making increasing use of lactic acid bacteria strains, which have very diverse properties and can be used for many different purposes. 


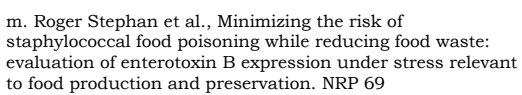

The future of nutrition research However, there is no overarching coordination in the entifically investigated and classified as potentially useful. The team recommends exploiting the food-preserving potential of bacteria more effectively. This includes the sharing of information on known strains: dat should be collected on a central platform for public and private partners and made freely and directly accessible.

In the "Staphylococci" project ${ }^{\mathrm{m}}$, researchers investigated the risk factors for bacterial food poisoning induced by factors on the formation of various staphylococcal toxins. They analysed the effect of high levels of salt, sugar, pickling salt and lactic acid (low pH), since these factors occur frequently during food processing and storage.

It emerged that the bacteria released less dangerous toxins, so called enterotoxins, in an environment that contained a high salt or sugar level. But the team also

To better address the health risks posed by Staphylococci, the researchers recommend developing new detection strategies, focussing on the quantification of enterotoxins present in the food instead of on counting the number of bacteria. The development of such detection syshelp to reduce food losses.

Two research groups participated in the European Joint Programming Initiative "A Healthy Diet for a Health Life" (JPI-HDHL) and paved the way for more efficient nutrition research.

It is generally accepted that dietary intake has an in fluence on health, but exactly how this happens differs from person to person: genetic predisposition, personal metabolism and environmental factors all play a role. ing the health impact of dietary intake. New biomarkers can be used to observe the relationship between dietary intake and health more effectively and predict it more reliably for specific population groups. The aim of the research project "Mirdiet" was to find new genetic biomarkers in the human body that provide indicators of the impact of dietary intake on health. The focus was on specific RNA molecules, or microRNAs. These play a role inone recids circulate in the blood and volunteer test subjects, the study analysed the effects of changes in diet on various microRNAs. Overall, the technical difficulties associated with measuring microRNAs in the bloodstream had a limiting effect on the results obtained. The scientists recommend continuing to search for biomarkers for food intake, despite the complexity of the methods used to quantify them. Technical progress could help overcome these obstacles by making it easier to measure the microRNAs circulating in the bloodstream, since these still have plenty of potential in

It is common practice today for nutritional scientists conducting investigations on food consumption to de pend on data from questionnaires. A new method hold out promise of more accurate results: dietary metaboand urine after the consumption of food) have been used to analyse the effects of food on people's health, but only a few types of food are currently covered by validated biomark tium "FOODBALL" proposed to (i) set up the technological tools necessary for the characterisation of these biomarkers, in particular nutritional metabolomics and databases allowing the quantification and identification of these biomarkers, and (ii) conduct human nutritional ries of foodstuffs covering the different food groups. University of Lausanne who participated in FOODBALL were able to identify biomarkers in the human metabolism that provide evidence of the consumption of milk cheese and soy drinks. Among the molecules produced after ingestion of dairy products are lactose-derived molecules whose appearance in the blood and urine of participants is indicative of their ability to digest lactose. conducted by the FOODBALL consortium to develop the field of personalised nutrition. In addition, the researchers identified metabolites derived from the amino acids tryptophan and phenylalanine as markers of the ingestion of fermented foods. These results have paved the way, through an observational human study, thus conducted in real conditions, to new work ained at che terising the impact of fermented foods on health. 


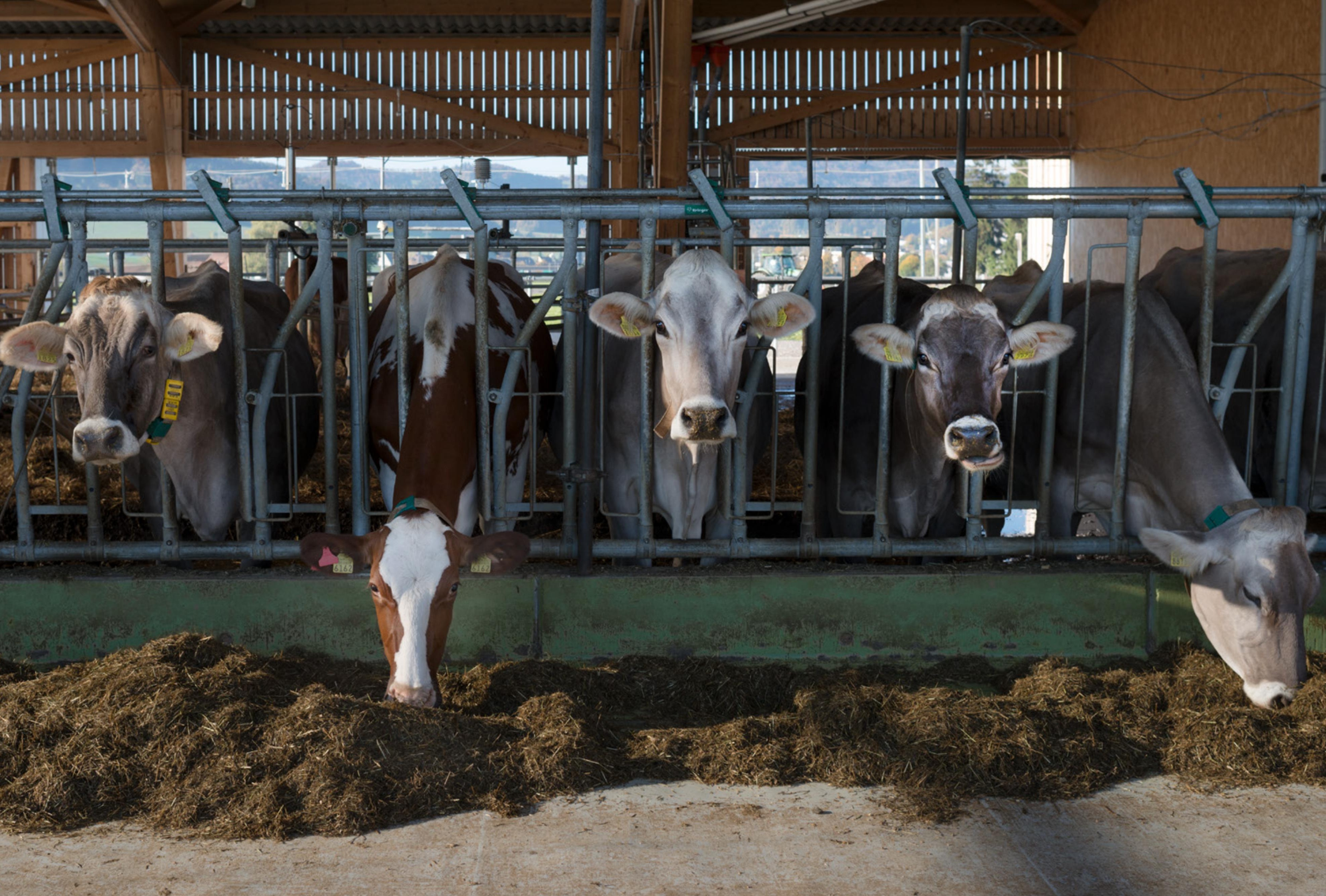




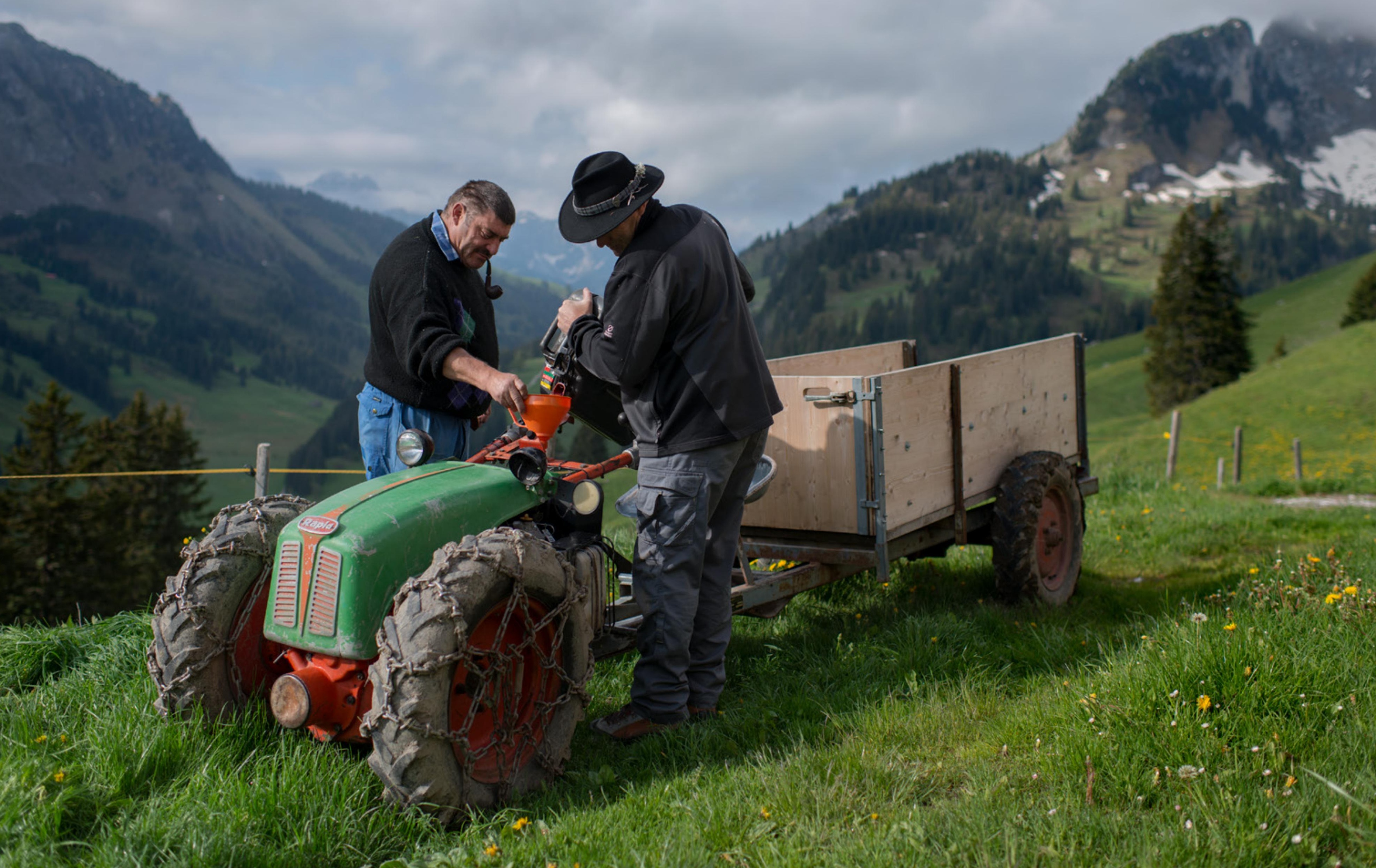




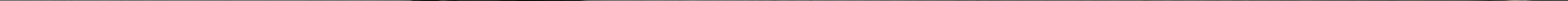




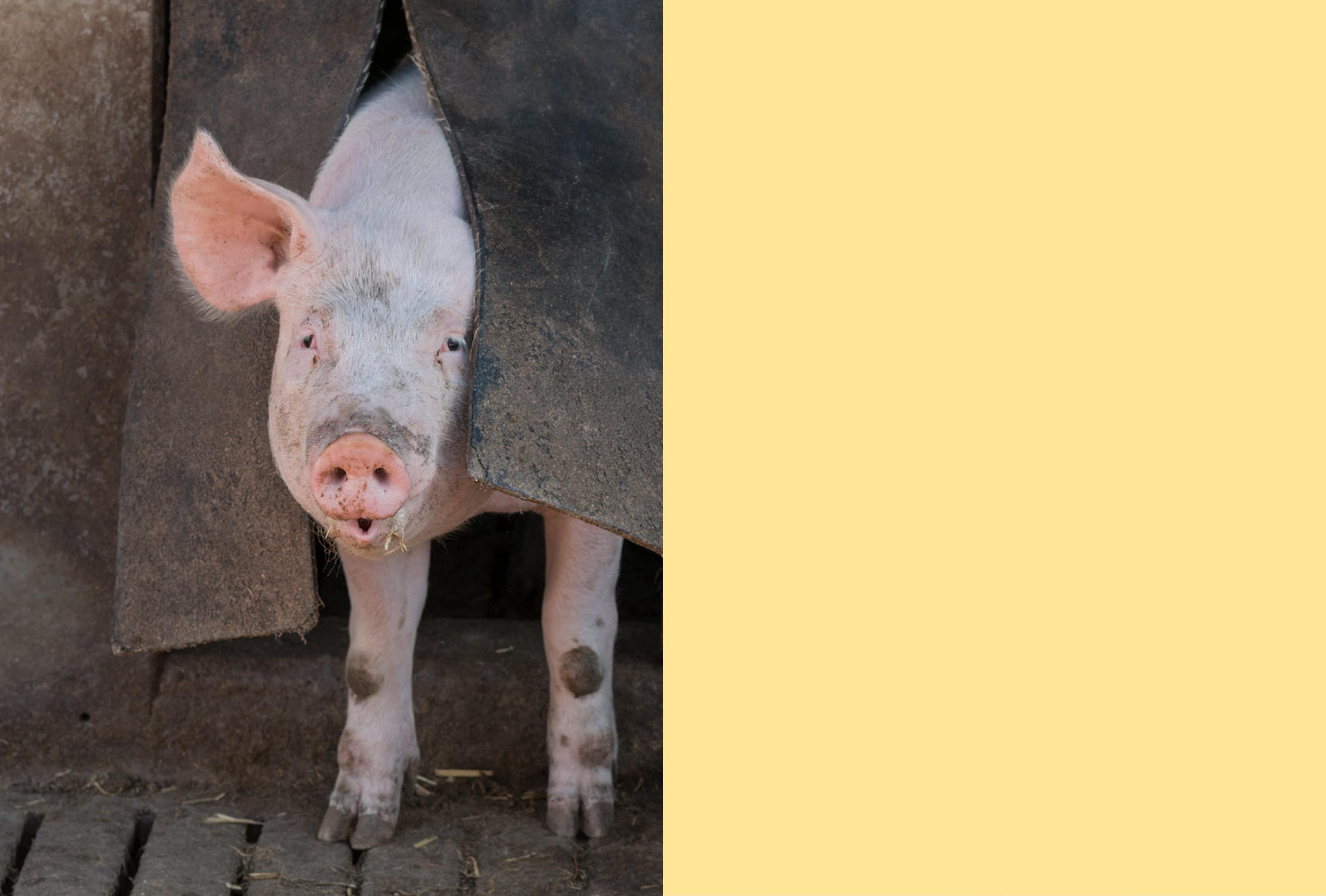




\section{Analysis of the Swiss policies bearing on the food system}

A NRP 69 research group analysed agricultural policies, food safety and public health policies, i.e. the policy fields that determine how Switzerland's food system is regulated. Their 列 In the much longer established field of agricultural policies. there are various conflicting interests. with different goals

Coherent food safety policy
Switzerland's food system is largely shaped by three different policy fields: quirements and public health policies. As part of NRP 69 a policy analysis ${ }^{a}$ was conducted to examine these three areas. The researchers were interested in the problems that policies aim to address, as well as the concrete measures employed for this purpose. They distinguished three types of measures: regulations that impose negative sanctions for non-compliance, positive incentives the results of their analysis.

Agricultural policies come at the beginning of the food system's value creation chain. In Switzerland, policies regulate food production in a variety of ways. The two main ways are incentives in the form of subsidies and regulations. Informal measures such as information

Many agricultural policy measures pursue several goals simultaneously. For example food production is supported through subsidies. Other subsidies are used to encourage the conservation of natural resources and animal welfare.

The important role of subsidies and regulations and the multitude of objectives they pursue can be traced back strong role of the federal govicultural pollcies and the

There are political instruments employed in agricultural policies that aim at limiting the environmental impact of agricultural production. The instruments used to pursue this goal are relatively new and/or of a rather non-binding nature.

As a policy field, food safety embraces all measures in tended to ensure that food can be consumed safely. food production and distribution through to consumption. Food safety is primarily guaranteed by strict legislation and control systems. Swiss food safety policies are relatively coherent and the Swiss regulation is fully harmonised with the EU. 


\section{The Swiss food system}

Switzerland's food system is largely shaped by three different policy fields.

Agricultural policies, food safety requirement and public health policies employ differen

ms in these areas.
Agricultural

policies

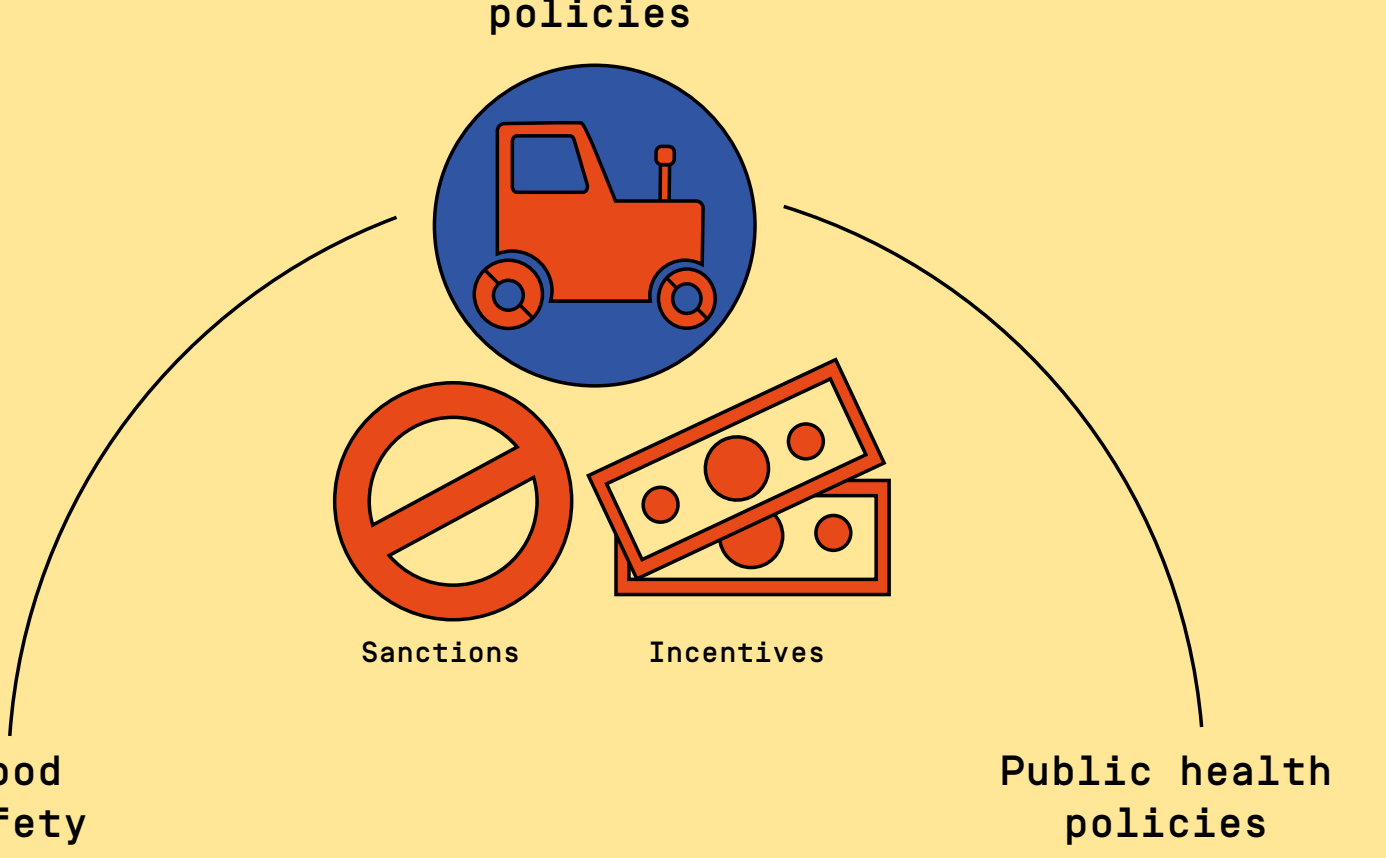

safety

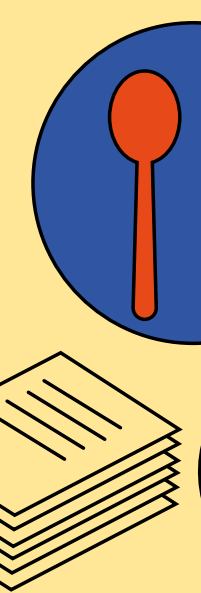

Legislation

Control

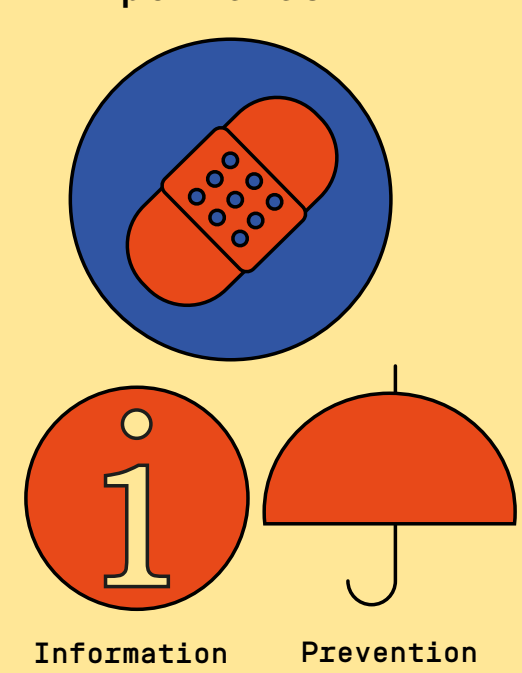

Measures to promote

healthy eating

Conflicting interests

in the Swiss food

system's policies Since large parts of public health represent new poli-
cy fields in Switzerland and are still finding their feet, not many instruments are yet in place. This may be a reason why most efforts to promote a healthy diet are information driven ${ }^{23}$. The information campaigns aim to strengthen consumers awareness of the need to eat healthily and give them the skills to do so.

Responsibility for health promotion in federal Switzerland lies largely with the cantons. The Swis and incentives to establish framework conditions that are conducive to healthy eating. As a result existing health policy measures are substantially less binding in nature than measures implemented in agricultural or food safety policies.

In Switzerland generally only a few regulations and in centives target consumers directly. A limited statutory more active role in public health. This means that government agencies must rely on the voluntary cooperation of both the industry and the Cantons in their efforts to encourage healthy eating decisions.

Hence, public health policies that actively foster healthy nutrition are less developed in Switzerland.

The EU has had a comprehensive, non-mandatory strategy on nutrition, overweight and obesity-related dated amongst others by Switzerland, was also recently launched to reduce the amount of sugar in processed

The researchers' policy analysis showed that Swiss food safety and pubic health policies pursue essentially coherent goals. No major conflicts were identified, either within the individual policy felds or in interaction with of Switzerland's international obligations towards the

Swiss agricultural policies are less coherent. Here, the policy analysis brought several potential areas of conflict to light. For instance, agricultural policies pursue two quite different objectives. The first is to increase access to foreign markets. In pursuit of this goal, agreements were negotiated with the European Union on parly elinitating on individual states. 

and makes corrective interventions in the market. This ply with certain environmental standards. As a result of these partially incoherent agricultural policy goals, individual measures need to be continually coordinated.

On the one hand, the government wants Swiss agriculture to be able to compete effectively in the European stringent regulations to protect domestic producers and the environment. Political goals have to be constantly adapted to accommodate these incoherencies.

There is thus a conflict between foreign trade and common market. Such conficts anise for example when agrcultural policies set out to secure supplies of agricultural produce while at the same time demanding higher environmental standards -in both cases with free market agricultural policies have to be kept carefully balanced.

The researchers regard the numerous cooperation ventures with private-sector partners in all three policy areas - agriculture, food safety and public health - as a further source of political tensions: Stakeholders such as processing companies, major retailers or pressure groups - for example environmental organisations, farming associations or health organisations - play a majo Ten in developing and implementing poltical measures. in Swiss agricultural policies

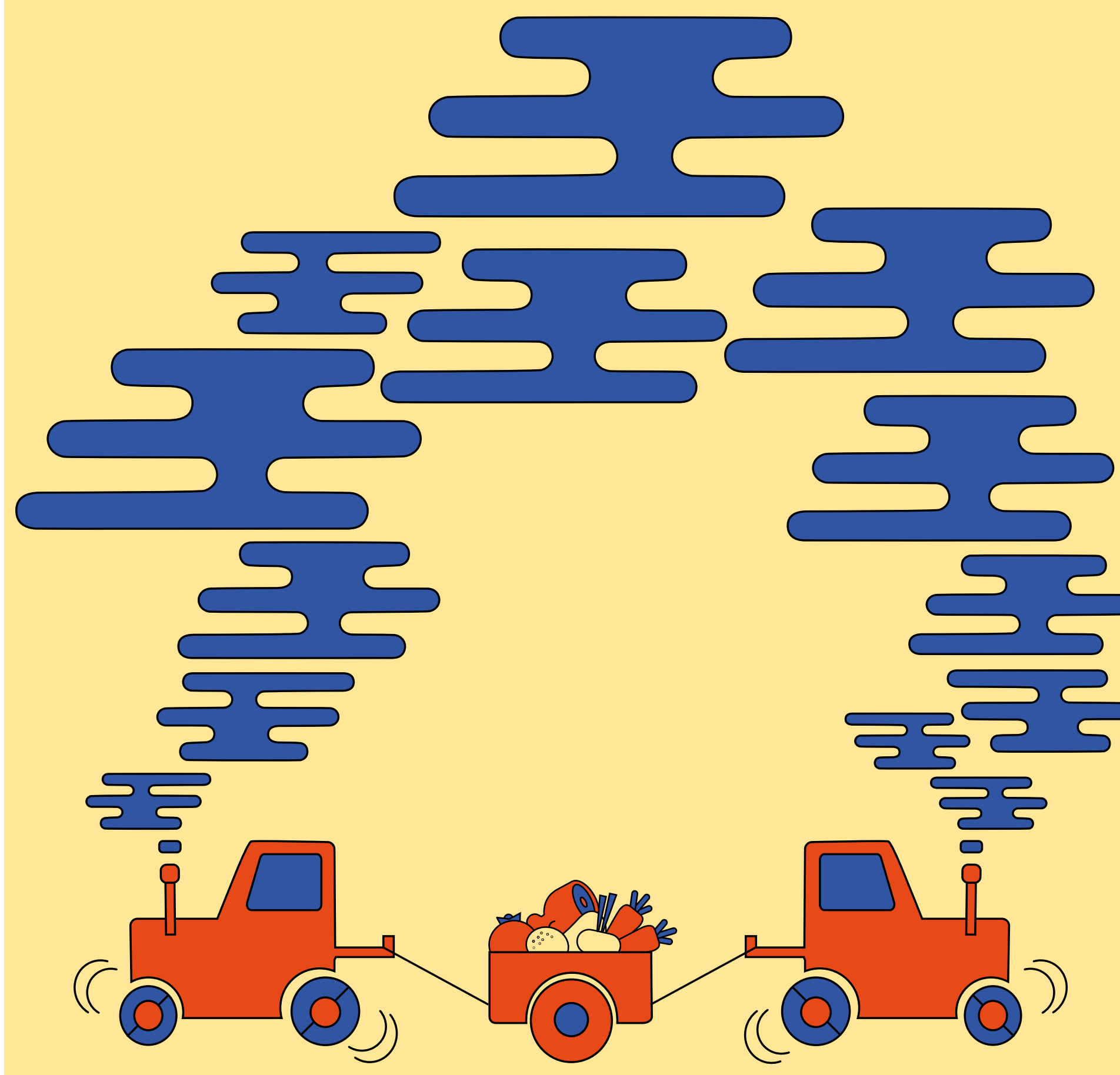




\section{Involve \\ consumers}

Consumers' influence on political decisions affecting the food system is still limited. In order to involve all parties affected,

the administration and political bodies should involve

level they involve food producers and industry representative
lativent

when shaping the future Swiss food system.

Greater say for consumers in decisions affecting the food system

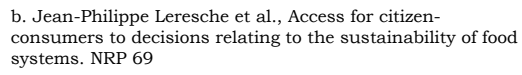

The NRP 69 "Citizen consumer" project $\mathrm{t}^{\mathrm{b}}$ revealed that, although consumers have more influence on nutrition than ever before, their influence on political decisions affecting the food system is still limited.

The research group recommends various measures to increase consumers influence on nutrition-related political decisions. These include extending the right of appeal to consurior protection organisations and giving ers also suggest that the State could give consumers a greater role in public duties, for example in contributing to specific food inspection tasks as already done on communal level or in creating new entities that could constitute a platform for closer cooperation between consumers and politics.

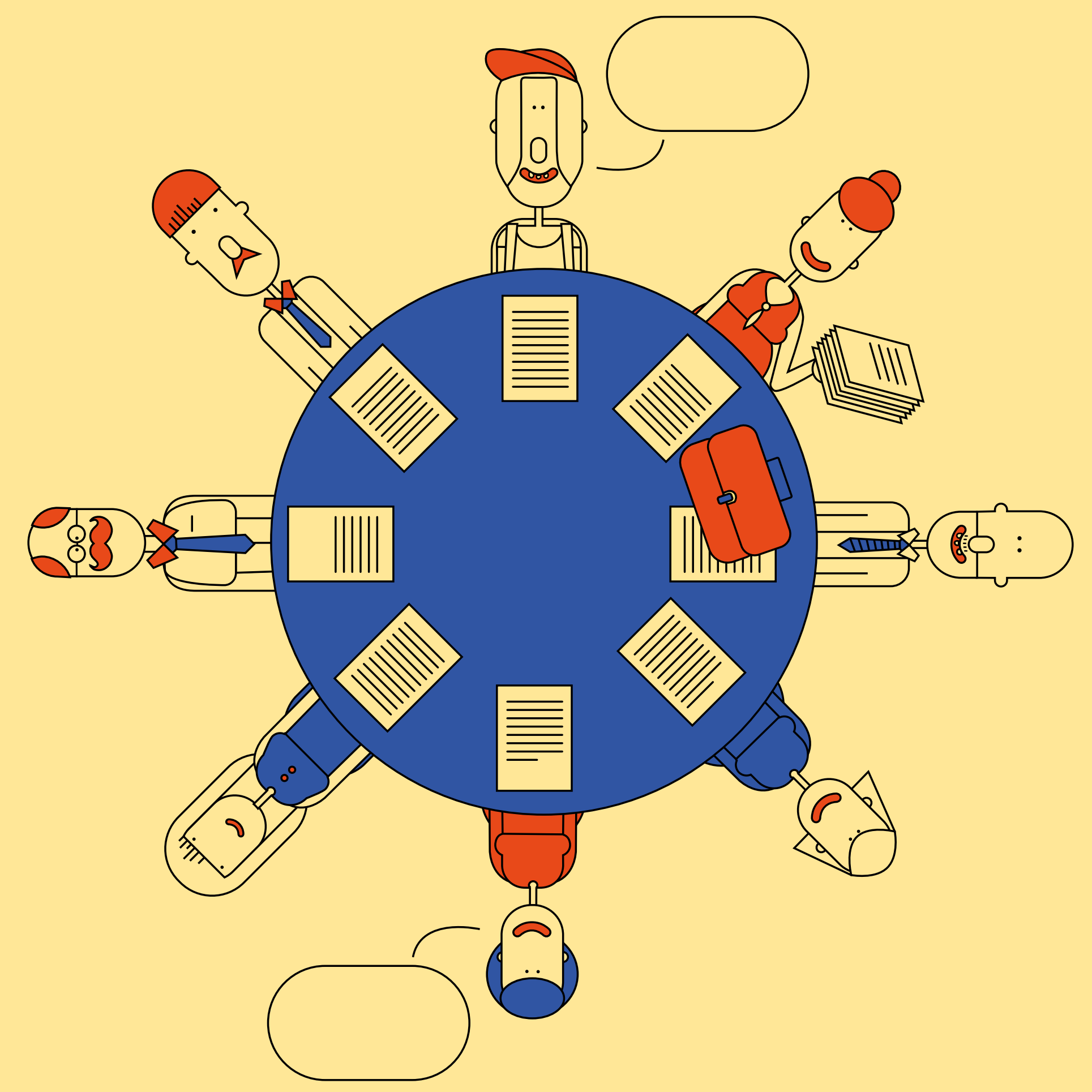




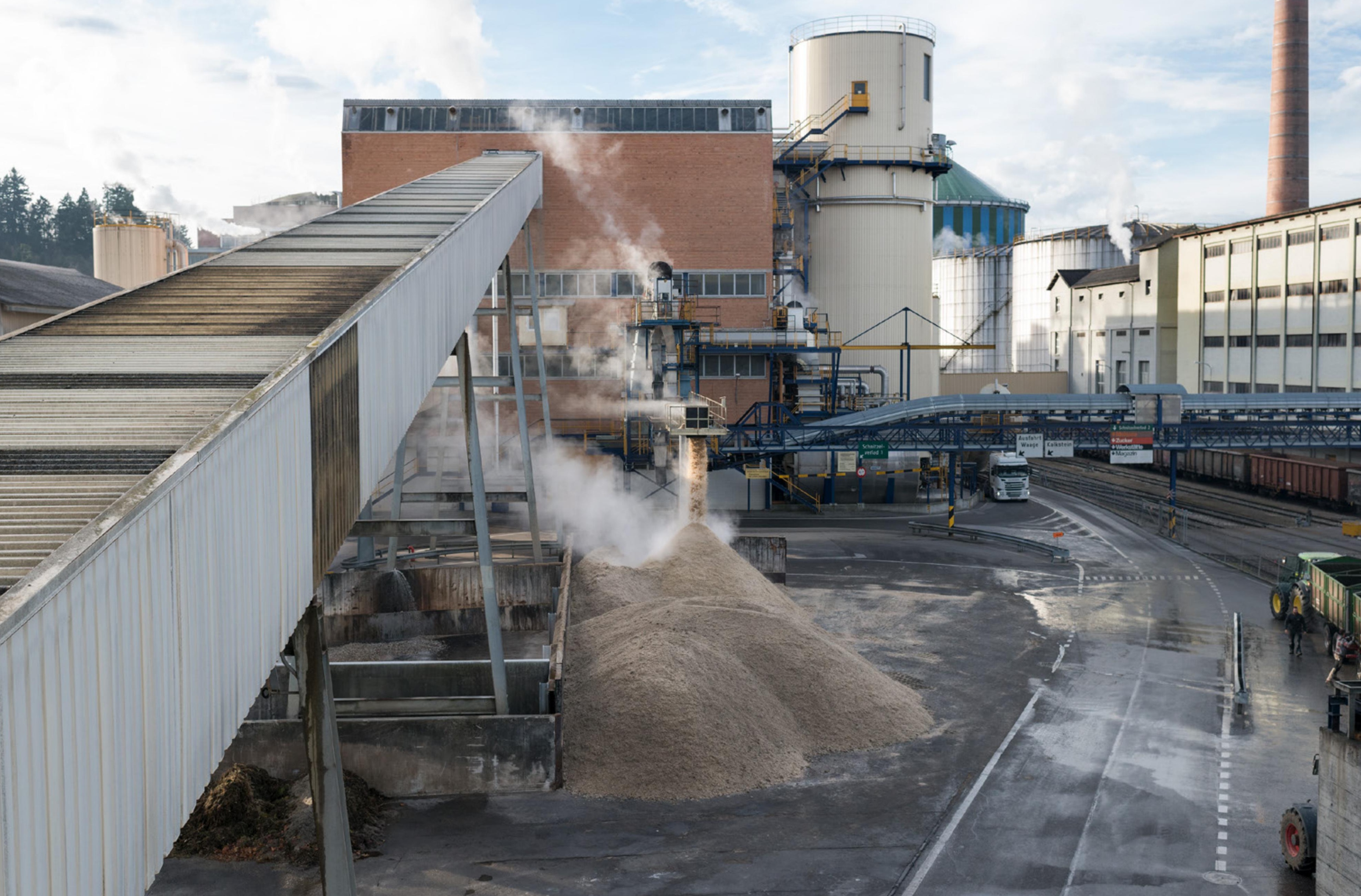




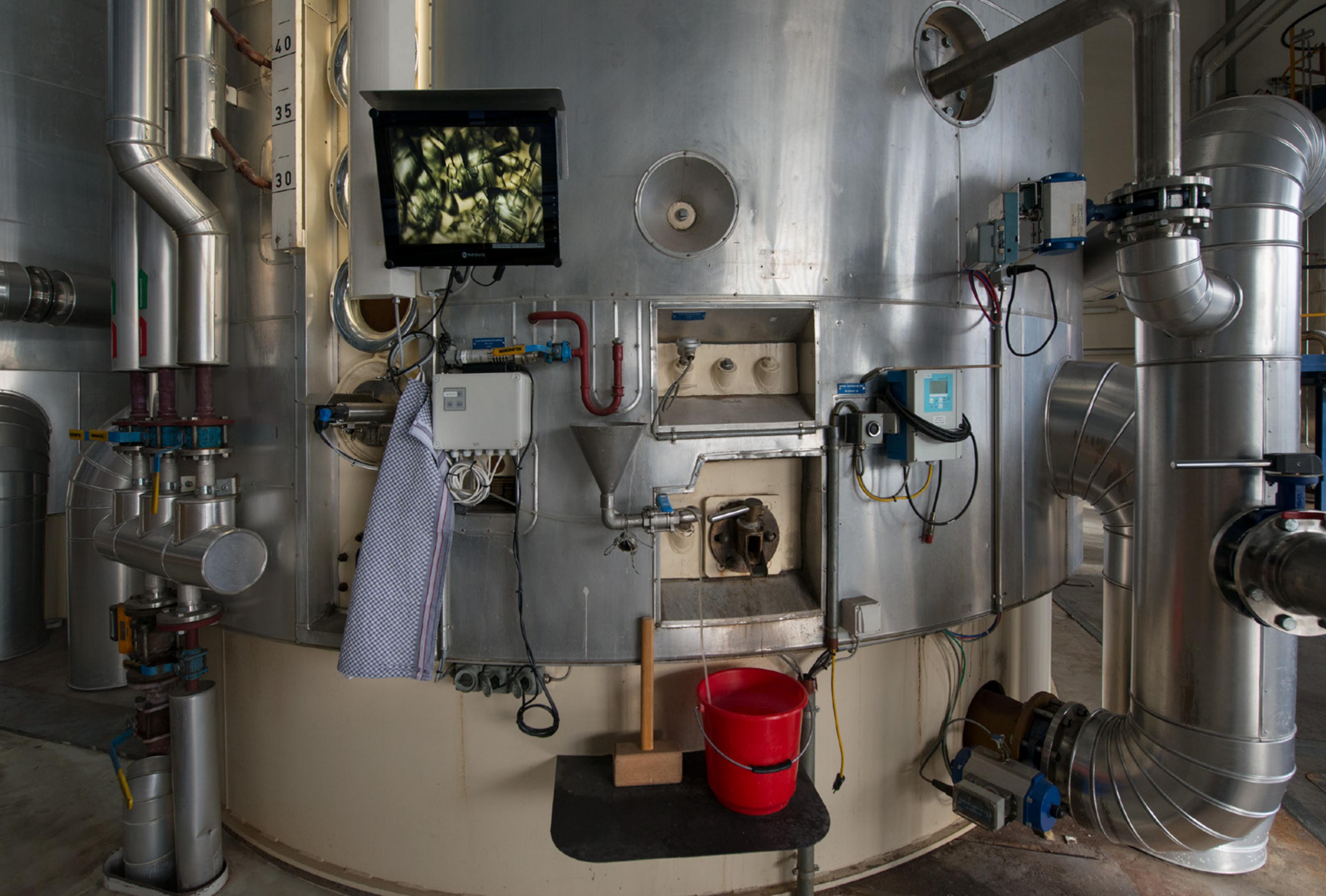




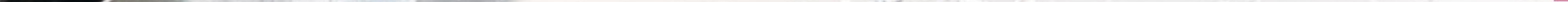


This final chapter presents conclusive remarks and one recommen dation. They arise from the results of the projects funded under
NRP 69 . But it also takes into account other national and international scientific findings on food and the environment, which have developed rapidly over the past decade.

Conclusive statements and recommendation NRP 69 was essentially an effort to meet the challeng-
es posed by the Swiss food system. The programme was designed to investigate the connection between sustainable food production, population health and nutrition. The supported projects have provided substantive findings and created knowledge in fields related to food production and processing, healthy diets and environmental protection.

This programme also has highlighted the complexity of the food system. Agriculture, processing, retailing, pub-
lic health and environmental changes emerge as societal, economic and health issues. They are strongly interrelated: given these complex interactions, any intervention can bring possible unintended effects across other areas.

Accordingly, NRP 69 covered a wide range of key questions, even though many projects, especially in the firs matic areas, the individual projects provided important new insights, developed practical recommendations and identified gaps in knowledge and its applications.

The broadness of the topic and the complex interactions require astute solutions. Dedicated efforts are needed to design an optimal food system for Switzerland, i.e. system allowing the provision of healthy food at affordable prices, produced with minimal negative impact on

The future of food: Switzerland has developed and implemented policies on
public health, on the environment and on agriculture. But there is nothing resembling a strategy on the food system, i.e. an integrated set of objectives related to environmental strategies, sustainable food production and an adequate human diet.

For this reason, the main overall recommendation of NRP 69 is: we need a Swiss food system strategy. This strategy must identify and implement cohesive interventions to achieve a healthier diet and more sustainable food production in Switzerland. It should take into account potential trade-offs between food production healthy diets and other socio-economic parameters such as employment, financial stability of the food sector or cultural hurdles. 
The overall aim of this strategy should be to enable a smooth transition of the Swiss food system, from the current situation to a healthy and sustainable diet.

To elaborate and implement this strategy, a multi-actor governmental advisory group should be set up, including representatives from the food production and propublic health sector and consumer representatives.

Many of the tools and recommendations developed within NRP 69 will be used by this advisory board. Closer contacts with the food industry will allow the inclusion of further research results.

Based on the results of NRP 69, three approaches were identified as being crucial to this transition: (1) involving consumers in political decision-making on the food system to generate acceptance and account for their needs and preferences, (ii) setting up a national action plan on ing and distribution of food. The structure of the recommendations is summarised in the following box.

\section{Recommendation}

\section{Develop an integrated Swiss food system strategy}

Switzerland needs a dedicated strategy addressing the future of the food sysem. This strateoy should be cohesive, simultaneously integrating healthy diet and sustainable food production all along the food chain.

The overall aim of this strategy should be to ensure an ample, healthy and sustainably produced diet for the Swiss population. Further, the strategy should identify and characterise the political tools and measures needed to ensure smooth transition to smarter, healthier and more sustainable food systems.

The results of NRP 69 highlight various elements that could be useful to this strategy, in order to make this transition a reality

1. Consumers representatives need to be closely involved in policy decisions concerning the whole food chain to foster consumers' acceptance and acshould stand at the same level as food producer representatives and industry representatives.

2. Much of the food produced is lost to consumption. There are promising ways nated in a national action plan against food waste.

3. The production, processing and distribution of food should be improved. production to consumers, to provide healthy food in a sustainable manner.

Furthermore, knowledge of the food system should be strongly expanded. Therefore, research and development in this area should be strengthened and supported by public funds. Further, interdisciplinary and transdisciplinary lines of research should be promoted involving industrial and academic partners.
Involve consumers in shaping the food system

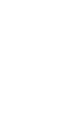

There is a growing concern from consumers about the 作

Consumers' influence on political decisions affecting the food system is still limited. In order to involve all partie affected, the administration and political bodies should involve consumers representatives in policy decision at the same level they involve food producers and infood system.

NRP 69 proposes several means to increase the influence of consumers on the food-related decision-making process: e.g. extending the right of appeal for consumer organisations, giving consumers the right to file class actions, and developing the cooperation between consumers, food producers and the industry.

Taking into consideration the interests of the consumfood system are necessary for consumers to make informed decisions based on the scientific evidence available. Moreover, an all-inclusive strategy would increase consumers' acceptance of necessary transitions within the food system.
National action plan against
food waste

a. Cornelia Palivan et al., protein polymer nanoreactors
preserve food quality NRP 69 .
There is a large body of evidence that a sizeable part of waste and food losses have a negative impact on the vironment when they are offset by increased food production. Therefore, reducing food waste is a promising approach to making the food system more sustainable.

In this context, modifying processing standards for foodstuffs could reduce losses in the production and processing stages. This is especially the case for stages focussing on the purely aesthetic properties, such as size
or appearance, of vegetables, potatoes or other products.

Another approach is to promote and apply innovative food preservation practices and new date marking methods, since consumers tend to throw away unopened food soon after its "best before" date. Information campaigns
about the correct interpretation of expiration date should be considered. Alternatively, new types of labels could be developed for certain foodsturs, to replace existing "best before" dates, such as those proposed by the "Nano-preservation" project ${ }^{a}$.

The first steps towards a national action plan on food waste have already been taken. In March 2019, the Swis Federal Council to draw up such an action plan ${ }^{26}$. 


\section{Improve production,}

processing and

distribution of food

b. Mathhias Stolze et al, Sustainable and healthy diets:
Trade-offs and synergies. NRP 69 The plan should list the various actions already im-
plemented in Switzerland and evaluate their impact. If necessary, it will propose additional multi-pronged measures in order to achieve the objectives of halving the edible food waste at retail and consumer levels and reducing food losses in agriculture, trade and the processing industry by 2030 . It will also have to provide parlament with an indicator with which to monitor the progress made concerned.

The Swiss food system needs forward-looking solutions which combine more sustainable food production, processing and distribution while also promoting a healthier diet.

The good news from the NRP 69 projects is that measures are available that contribute to more sustainable ier diet. For example, reducing meat and sugar consumption would both improve consumers' health and make food production more sustainable, as the project "Recommendations for sustainable and healthy diets" proposed.

Several NRP 69 projects proposed promising solutions for healthier nutrition as well as better conditions for the production of healthy and/or more sustainable food. in the solutions cou

On the other hand, the cross-cutting project "Recommendations for sustainable and healthy diets"b also highlighted the limits of healthy nutrition and sustainable food production and the conflicts between the two. For this reason, efforts to inprove the Swiss food system s a whole and involve all actors along the food chain.
Food, health and the environment are widely researched internationally. New knowledge is actively generated, identifying many biomedical, epidemiological and environmental mechanisms linking food with health and environmental effects.

The 2019 World Resources Institute report ${ }^{27}$ emphasizes that $R \& D$ is crucial to the global future of food: the report "has consistently emphasized the need for additiona sustainable food future. It has also stressed adequate funding to pursue research into the most promisin leads. Meeting these needs will require increasing the quantity of funding well beyond what is currently available, putting more effort into the direct application of research, and pursuing critical technological breakthroughs. R\&D efforts should focus on increasing pro-

NRP 69 is Switzerland's response to this statement. The results if the reserchers dense to this statement. The results of the researchers demonstrate the strength of riculture and the environment. The achievement of the researchers was to develop scientific knowledge and practical, evidence-based solutions to concrete issues. Some projects proposed novel approaches to problems old and new. The individual projects supported by NRP 69 produced significant results bearing on different areas of the tood chain (summarised in chapters 2,3 and 4). Most of

Switzerland has strong research capabilities, both in the public and the private sectors; excellent research group are active at the highest level, winning internationa recognition in Europe as well as globally. In particular Switzerland has proven capacities in the development of new products and the application of strategies based on fundamental science in the private food sector. This high level of R\&D should be maintained by implementing

NRP 69 underlines the need for integrated thinking and collaboration with all actors along the food chain There are few bodies or activities working coherently
on research and implementation strategies across the food system, and there are even fewer bodies bringing together scientists, industrial and governmental representatives. This is underlined by the fact that only a few research groups submitted interdisciplinary or transdisciplinary projects for NRP 69. Hence, research ent perspectives on the food system should be strongencouraged. 
In this context, collaborations between industrial and academic research should also be strengthened, perhaps inspired by the pattern of collaboration linking the phar-

One way to encourage research in that direction may be the setting up of a National Centre of Competence in Research (NCCR). The Confederation uses this funding instrument to support long-term research projects science, economy and society.

Another way involves the new support structure aimed at bringing together SNSF-funded researchers and stakeholders to develop research findings into practical applications. This funding scheme, called BRIDGE, is jointly offered by the SNSF and Innosuisse - the Swiss Innovation Agency.

Swiss entities (academic, governmental and private sector) should be encouraged to develop and maintain at European and/or at global level. Emphasis should be placed on collaborations with the European Union, for e.g. within Joint Programming Initiatives (JPI), one of which is devoted to the same subject: A Healthy Diet for a Healthy Life (HDHL).

In order to quantify the success of the efforts described above and to identify further need for action, a monibe established. This should make it possible to monitor the changes in environmental parameters and human diet based on specific interventions. It is important to note that Switzerland is lagging behind other countries: the first nationwide survey on diet was conducted only in 2013.

Similarly, academic research should be encouraged to develop experimental or quasi-experimental approaches to evaluate the efficacy and the impact of interventions. troduction of the Nutri-Score label in France ${ }^{28}$.

It needs to be stressed that identifying and reducing the gaps in scientific knowledge is essential in order to offer expert knowledge to citizen-consumers and decision-makers. Food, probably more than other areas, is targeted by a large and increasing number of rules, opinions and advice, coming from all sorts of actors. And scientific evidence does not necessarily carry more weigh than public opinion. For this reason, clear and well-reato promote a sustainable food production is needed.

By the same token, NRP 69 underlines the urgent need to develop an integrated, cross-sectoral Swiss food system strategy to simultaneously improve people's health and the environment's sustainability. 


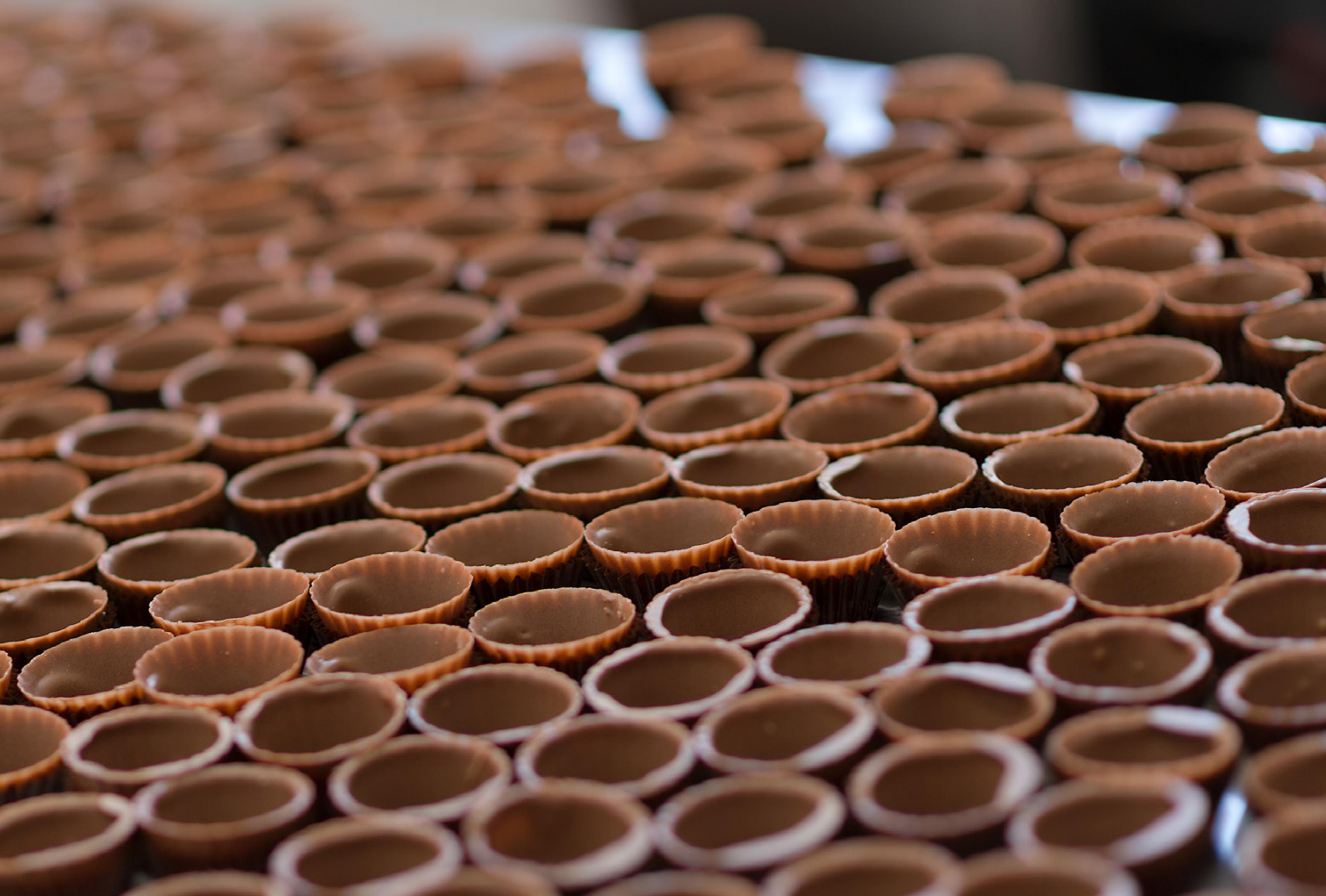




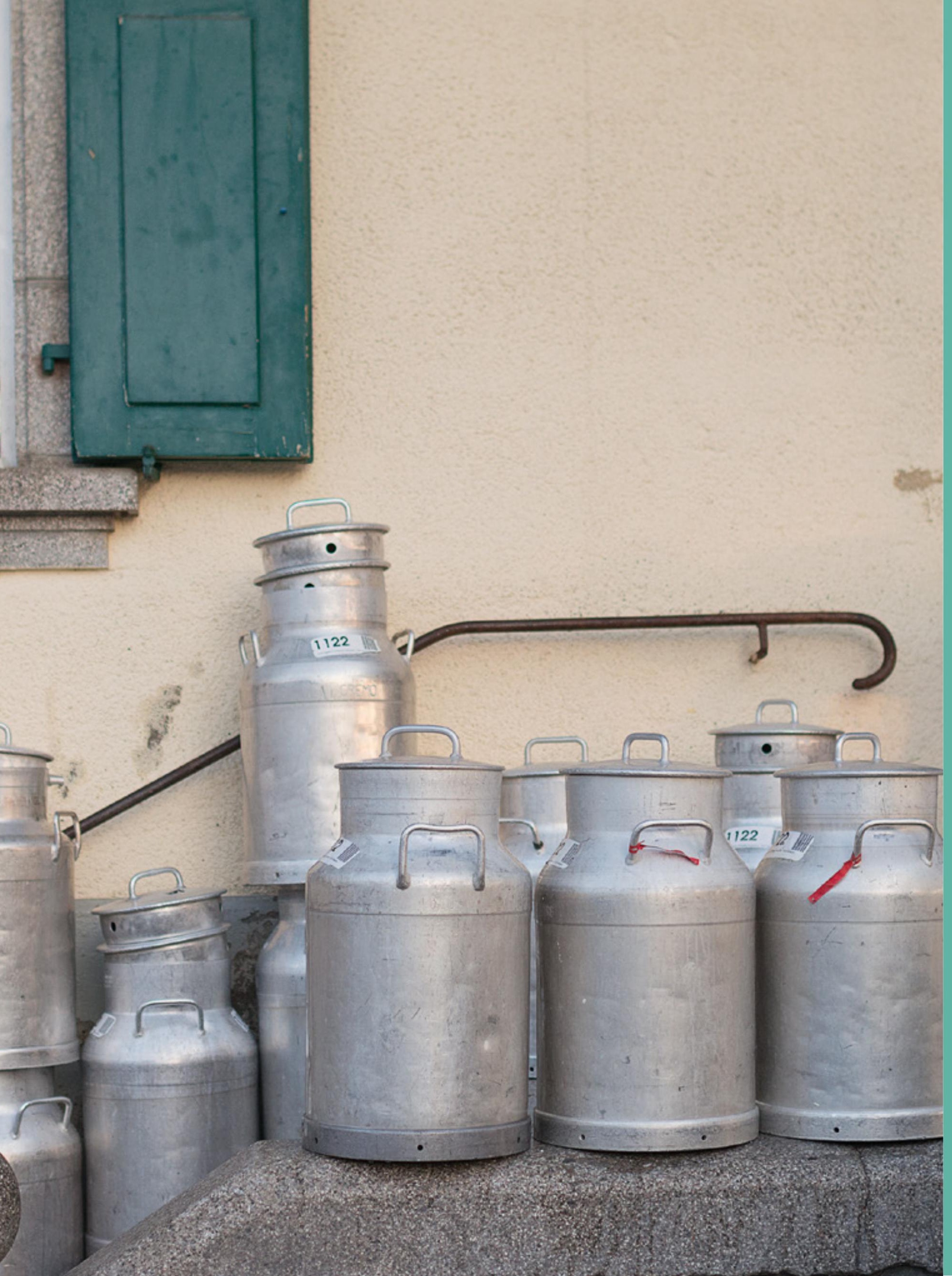




\section{Foodstuffs}

According to the Swiss Federal Act on Foodstuffs and Utility $^{29}$, foodstuffs are defined as "all substances or products that are intended or may reasonably be expected to be consumed by human beings in a processed, partly processed or unprocessed state".

\section{Food system}

Food system includes all elements and activities that relate to production, transport, processing, packaging storage, retail, consumption, loss and waste ${ }^{3 / 30}$.

\section{Healthy diets}

Healthy diets are characterised by "an appropriate caloric intake and consist of a diversity of plant-based foods, low amounts of animal source foods, unsaturated rather
than saturated fats, and small amounts of refined grains, highly processed foods, and added sugars" $3 / 30$.

\section{Public health}

Public health is defined as the art and science of developing and implementing appropriate responses to the oping and implementing approprath
health needs of the population.

\section{Sustainable development}

According to the Food and Agriculture Organisation of the United Nations (FAO), sustainable development is defined as "the management and conservation of the hatural resource base, and the orientation of technoto ensure the attainment and continued satisfaction human needs for present and future generations. Such sustainable development $[\ldots]$ conserves land, water plant and animal genetic resources, is environmentally non-degrading, technologically appropriate, economically viable and socially acceptable" ${ }^{\text {"32 }}$.

\section{Food waste}

According to the FAO, food waste refers to the discarding or alternative (non-food) use of food that is safe and nutritious for human consumption ${ }^{10}$. 


\section{Food loss}

According to the FAO, food loss refers to any food that is lost in the supply chain between the producer and the market $^{10}$.

\section{Food security}

Food security is defined (...) as "a situation that exists when all people, at all times, have physical, social, and
economic access to sufficient, safe and nutritious food that meets their dietary needs and food preferences for an active and healthy life"s.

\section{The FAO definition of food processing}

The FAO definition of food processing is "any change that is made to a food to alter its eating quality or shelf processing as a classification key, i.e. (i) Unprocessed or minimally processed foods, (ii) Processed culinary ingredients, (iii) Processed food, (iv) Ultra-processed foods. 
2. Lang Tim, Barling David, Caraher Martin, Food Policy: Integrating Health, Environment and Society, Oxford, OUP, 2009.

3. United Nations Environment Programme [UNEP], International Resource Panel, Global Resources Outloo

4. Federal Office of Statistics [FSO], Food and Agriculture : Pocket Statistics, 2019.

5. United Nations, Department of Economic and Social Affairs, News, World population to reach 9.8 billion in 2050, 2017.

6. Food and Agriculture Organisation of the UN [FAO], Agriculture to 2050 - The challenges ahead, 2009.

7. Food and Agriculture Organisation of the UN [FAO], Agricultural development Economics Division, State of food security and nutrition in the world, 2019.

8. McMichael Anthony J, Powles John W, Butler Colin D, Uauy Ricardo, Food, livestock production, energy, mate change, and health, Lancet 2007; 370: 1253-63.

9. Food and Agriculture Organisation of the UN [FAO], tion, 2010

10. Food and Agriculture Organisation of the UN [FAO], Global Food Losses and Food Waste - Extent Causes and Prevention, 2011.

11. Federal Office for the Environment [FOEN], Food Waste in Switzerland, 2018

12. Mengheri Elena, Diet Quality Is Associated with Microbial Diversity and Host Health, The Journal of Nutrition, 2019.

13. Federal Office of Public Health [FOPH], Cost of obesity in Switzerland in 2012, 2014.

14. Swiss Nutrition Society, press release, Des études universitaires le sonnel de qualité augmente la motivation au travail et les performances, 29.09.2016.

15. McLean Erin et al., Worldwide prevalence of anaemia, WH Vitamin and Mineral Nutrition Informatio sue $4,2009,444-454$.

16. Cochrane UK, Vitamin D supplements in pregnancy: what's the latest evidence?, 2019. 
17. ETH Zürich, World Food System Center, Foresight Study: Research for a Sustainable Swiss Food System, 2015.

18. Federal Office for Environment [FOEN], Umweltziele Landwirtschaft, 2016.

19. Federal Council, OAS 913.1, Ordinance on Structural Improvements in Agriculture, 2019.

20. Proviande, Statistics, Meat Consumption 2017 in Switzerland, 28.03.2019.

21. The United Nations, The 2030 Agenda for Sustainable Development, 2015.

22. European Commission, Press release, Preventing food waste, promoting Circular Economy: Commission adopts common methodology to measure food wast

23. Swiss Federal Office of Public Health [FOPH] National health strategies, 2018.

24. Federal Food Safety and Veterinary Office [FSVO] Swiss Nutrition Strategy 2017-24.

25. European Commission, EU FRAMEWORK FOR NATIONAL INITIATIVES ON SELECTED NUTRIENTS, Added Sugars Annex, 2016.

26. Postulate 18.3829 by National Councillor Isabelle Chevalley: action plan against food waste, 2018.

27. World Resources Institute, Creating a sustainable food future. A Menu of Solutions to Feed Nearly 10 Billion People by 2050. Final Report, 2019.

28. Egnell Manon et al., Front-of-Pack Labeling and the Nutritional Quality of Students' Food Purchases: 3-Arm Randomized Controlled Trial, American Journal

29. Federal Act on Foodstuffs and Utility Articles, (Foodstuffs Act, FSA), 2013.

30. Willett Walter $\mathrm{C}$ et al., Food in the Anthropocene: the EAT-Lancet Commission on healthy diets from sustainable food system, Lancet, Vol. 393, Issue 10170 February 2019, 447-492.

31. Monteiro Carlos A et al., NOVA. The star shines bright, World Nutrition, Vol. 7, Issue 1-3, January-

32. Food and Agriculture Organization of the United Nations [FAO], Sustainability Assessment of Food and Agriculture systems (SAFA), 2014.

33. Food and Agriculture Organisation of the UN [FAO], Global Initiative on Food Loss and Waste Reduction, 
Annexe 1

ist of selected publications by $N$ projects funded
2019

The Fate of $\mathrm{Zn}$ in Agricultural Soils: A Stable Isotope Approach to Anthropogenic Impact, Soil Formation, and Soil-Plant Cycling.

Imseng M, Wiggenhauser M, Müller M, Keller A, Frossard E, Wilcke W, Bigalke

Environ Sci Technol. 2019 Apr 16;53(8):4140-4149. doi: $10.1021 /$ acs.est.8b03675. Epub 2019 Apr 5 .

Towards an understanding of the $\mathrm{Cd}$ isotope fractionation during transfer from the soil to the cereal grain. Imseng M, Wiggenhauser M, Keller A, Müller M, Rehkämper M, Murphy K, Kreissig K, Frossard E, Wilcke W, Bigalke $\mathrm{M}$

Pollut. 2019 Jan:244:834-844.

doi: 10.1016/j.envpol.2018.09.149. Epub 2018 Oct 12 . PMID: 30390457

Cultural Differences in Diet and Determinants of Diet Quality in Switzerland: Results from the National Nutrition Survey menuCH. Pestoni G, Krieger JP, Sych JM, Faeh D, Rohrmann S. Nutrients. 2019 Jan 9;11(1). pii: E126. doi: $10.3390 /$ nu11010126.

PMID: 30634520

RE-AIM evaluation of a one-year trial of a combined educational and environmental workplace intervention to lower salt intake in Switzerland.

nblätter J, Jent S, SiegenPrev Med Strazzullo P, Luta X. PMID: 31516815

Using isotopes to trace freshly applied cadmium through mineral phosphorus fertilization in soil-fertilizer-plan systems.

Wiggenhauser M, Bigalke M, Imseng M, Keller A, Rehossard E.

doi: 10.1016/j.scitotenv.2018.08.127. Epub 2018 Aug 14 PMID: 30138877

2018

Dietary Patterns Are Associated with Cardiovascula and Cancer Mortality among Swiss Adults in a Census-Linked Cohort.

Kiser J, Cabaset S, Pestoni G, Rohrmann S, Faeh D Nutrients. 2018 Mar 7:10(3) pii: E313.

doi: $10.3390 /$ nu 10030313 . 
Dietary Patterns and Their Sociodemographic and Lifestyle Determinants in Switzerland: Results from the National Nutrition Survey menuCH.

Krieger JP, Pestoni G, Cabaset S, Brombach C, Sych J, Schader C, Faeh D, Rohrmann S.

Nutrients. 2018 Dec 29;11(1). pii: E62.

doi: $10.3390 /$ nu 11

Enhancing enterocyte fatty acid oxidation in mice affects glycemic control depending on dietary fat.

Dichel L Burkard , Kaufman S, Diaz AA, Weissfeld N, De Bock K, PripBuus C, Langhans W, Mansouri A.

Sci Rep. 2018 Jul $17 ; 8(1): 10818$.

doi: 10.1038/s41598-018-29139-6.

PMID: 30018405

Prevalence and determinants of vitamin D deficiency in the third trimester of pregnancy: a multicentre study in

Krieger JP, Cabaset S, Canonica C, Christoffel L, Richard A, Br J Nutr. 2018 Feb;119(3):299-309. doi : 10.1017/S0007114517003634. Epub 2018 Jan 10. PMID: 29318983

Exploiting multicompartment effects in triple-ech steady-state T2 mapping for fat fraction quantification

Liu D, Steingoetter A, Curcic J, Kozerke S.

doi: $10.1002 / \mathrm{mrm} 26680$. Evub 2017 Ma 25.

PMID: 28342191 Fate of $\mathrm{Cd}$ in Agricultural Soils: A Stable Isotope Ap-
proach to Anthropogenic Impact, Soil Formation, and Soil-Plant Cycling.

Imseng M, Wiggenhauser M, Keller A, Müller M, Rehkämper M, Murphy K, Kreissig K, Frossard E, Wilcke W, Bigalke M.

Environ Sci Technol. 2018 Feb 20;52(4):1919-1928. doi: $10.1021 /$ acs

Tailoring Emulsions for Controlled Lipid Release: Establishing in vitro-in Vivo Correlation for Digestion of Lipids. Scheuble N, Schaffner J, Schumacher M, Windhab EJ, Liu D, Parker H, Steingoetter A, Fischer ACS Appl Mater Interfaces. 2018 May 30;10(21):1757117581.

doi: 10.1021/acsami.8b02637. Epub 2018 May 16. PMID : 29708724

Cutting through conflicting prescriptions: How guidelines inform "healthy and sustainable " diets in Switzerland. Godin L, Sahakian M.

Appetite. 2018 Nov 1;130:123-133

doi: 10.1016/j.appet.2018.08.004. Epub 2018 Aug 4. PMID: 30086323
Clustering of Pan- and Core-genome of Lactobacillus Inglin RC, Meile L, Stevens MJA.

BMC Genomics. 2018 Apr 24;19(1):284

doi: $10.1186 / \mathrm{s} 12864-018-4601-5$.

PMID: 29690879

Just a subtle difference? Findings from a systematic review on definitions of nutrition literacy and food literacy Health Promot Int. 2018 Jun 1:33(3):378-389.

doi: $10.1093 /$ heapro/daw084. Review.

PMID : 27803197

A short food literacy questionnaire (SFLQ) for adults : Findings from a Swiss validation study.

Gréa Krause C, Beer-Borst S, Sommerhalder K, Hayoz S, Abel T.

Appetite. 2018 Jan 1;120:275-280.

doi: 10.1016/j.appet.2017.08.039. Epub 2017 Sep 11. PMID: 28912107

New horizons for future research - Critical issues to consider for maximizing research excellence and impact. Langhans W, Adan R, Arnold M, Banks WA, Card JP, Dailey MJ, Daniels D, de Kloet AD, de Lartigue G, Dickson S, Fedele S, Grill HJ, Jansson JO, Kaufman S, Kolar G, Krause E, Lee SJ, Le Foll C, Levin BE, Lutz TA, Mansouri A, Moran TH, Pacheco-Lopez G, Ramachandran D, Raybould H, Rinaman L, Samson WK, Sanchez-Watts G, KL Templeton B, Trapp S, Tso P, Watts AG, Weissfeld $\mathrm{N}$, Williams D, Wolf

doi: 10.1016/j.molmet. 2018.05.007. Epub 2018 May 12. No abstract available.

\section{PMID: 29886182}

Zinc isotope fractionation during grain filling of whea and a comparison of zinc and cadmium isotope ratios in identical soil-plant systems.

, Imseng M, Keller A, Archer .

ul :219(1):195-205

doi: $10.1111 / \mathrm{nph}$ 15146. Epub 2018 Apr 26.

PMID: 29696652

Oleoylethanolamide-induced anorexia in rats is associated with locomotor impairment

Fedele S, Arnold M, Krieger JP, Wolfstädter B, Meyer U, Langhans $\mathrm{W}$, Mansouri A.

doi: $10.14814 /$ phy2 13517

PMID: 29388342 
Study design and baseline characteristics of a combined educational and environmental intervention trial to lower sodium intake in Swiss employees.

Beer-Borst S, Luta X, Hayoz S, Sommerhalder K, Krause CG, Eisenblätter J, Jent S, Siegenthaler S, Aubert R, Haldimann M, Strazzullo P.

BMC Public Health. 2018 Apr 2;18(1):421.

doi: $10.1186 / \mathrm{s} 12889-(-203$

Responses of Oat Grains to Fusarium poae and F. langsethiae Infections and Mycotoxin Contaminations.

Martin C, Schöneberg T, Vogelgsang S, Mendes Ferreira CS, Morisoli
Mascher F.

Toxins (Basel). 2018 Jan 20;10(1). pii: E47.

doi: $10.3390 /$ toxins 1001004

PMID: 29361693

The relationship of health/food literacy and salt awareness to daily sodium and potassium intake among workplace population in Switzerland.

Luta X1, Hayoz S1, Gréa Krause C1,

Cardiovasc Dis. 2018 Mar;28(3):270-277. PMID: 2931097

\section{7}

Amyloid fibril systems reduce, stabilize and deliver bioavailable nan

Shen Y, Posavec L, Bolisetty S, Hilty FM, Nyström G, Kohlbrecher J, Hilbe M, Rossi A, Baumgartner J, Zimmermann MB, Mezzenga R.

Nat Nanotechnol. 2017 Jul;12(7):642-647.

doi: 10.1038/nnano.2017.58. Epub 2017 Apr 24.

A nudge in a healthier direction: How environmental the pursue their weight-control goal.

Stämpfli AE, Stöckli S, Brunner TA.

doi: 10.1017/ Mar 1;110:94-102. PMID: 27915080

Socioeconomic Determinants of Sodium Intake in Adult Populations of High-Income Countries: A Systematic Review and Meta-Analysis.

Petrovic D, Marques-Vidal P, Bochud , Stholth 2017

doi: 10.2105/AJPH.2016.303629. Epub 2017 Feb 16. Review.

Fifteen-year trends in the prevalence of barriers to healthy eating in a high-income country.

C, Khalatbari-Soltani $S$, Stringhini $s$, Marques-Vidal P.
Am J Clin Nutr. 2017 Mar;105(3):660-668 doi: 10.3945/ajcn.116.143719. Epub 2017 Jan 25. PMID: 28122785

Food loss reduction from an environmental, socio-economic and consumer perspective - The case of the Swiss potato market.

Willersinn C, Mouron P, Mack G, Siegrist M.

Waste Manag. 2017 Jan;59:451-464.

2016 Oct 15

Ion-Induced Hydrogel Formation and Nematic Ordering of Nanocrystalline Cellulose Suspensions.

Bertsch P, Isabettini S, Fischer P.

Biomacromolecules. 2017 Dec $11 ; 18(12): 4060-4066$. doi: 10.1021/acs.biomac.7b01119. Epub 2017 Oct 20. PMID: 2902833

Metabolic Adaptation of the Small Intestine to Short- and Medium-Term High-Fat Diet Exposure.

Andran $D$, Fedele $S$ Krieger JP, Langhans W, Mansouri A.

J Cell Physiol. 2017 Jan;232(1):167-75. doi: $10.1002 /$ jcp.25402. Epub 2016 Apr 28. PMID: 27061934

Intestinal SIRT3 overexpression in mice improves whole body glucose homeostasis independent of body weight. Ramachandran D, Clara R, Fedele S, Hu J, Lackzo E, Huang JY, Verdin E, Langhans W, Mansouri A.

doi: 10.1016/j.molmet.2017.07.009. Epub 2017 Jul 18.

PMID: 29031725

Gastric and Postgastric Processing of 13C Markers Renders the $13 \mathrm{C}$ Breath Test an Inappropriate Measurement Method for the Gastric Emptying of Lipid Emulsions in Healthy Adults.

Parker HL, Liu D, Curcic J, Ebert MO, Schwizer W, Fried M, Steingoetter A.

ul:147(7):1258-1266

doi: 10.3945/jn.117.248765. Epub 2017 May 31.

PMID: 28566523

Accelerating MRI fat quantification using a signal model-based dictionary to assess gastric fat volume and distribution of fat fraction.

Liu D, Steingoetter A, Parker HL, Curcic J, Kozerke S.

Magn Reson Imaging. 2017 Apr:37:8

. PMID: 27867052

Microfluidic Technique for the Simultaneous Quantification of Emulsion Instabilities and Lipid Digestion Kinetics. Scheuble N, Iles A, Wootton RCR, Windhab EJ, Fischer P, Elvira KS.

Anal Chem. 2017 Sep 5;89(17):9116-9123. doi: 10.1021/acs.analchem.7b01853. Epub 2017 Aug 18 . PMID: 28770989 
Highly Selective Volatile Organic Compounds Breath Analysis Using a Broadly-Tunable Vertical-External-Cavity Surface-Emitting Laser.

Tuzson B, Jágerská J, Looser H, Graf M, Felder F, Fill M, Tappy L, Emmenegger L.

Anal Chem. 2017 Jun 20;89(12):6377-6383. doi: $10.1021 /$ acs.analchem.6b04511. Epub 2017 May 26.
PMID: 28514136

Complete and Assembled Genome Sequence of Lactobacillus plantarum RI-113 Isolated from Salami.

Genome Announc. 2017 Apr 20 5(16). pii: e00183-17. doi: 10.1128/genomeA.00183-17.

PMID: 28428294

Complete and Assembled Genome Sequence of Vagococcus teuberi DSM 21459T, a Novel Species Isolated from Fermented Cow Milk in Mali.

Genome Announc. 2017 Jan 26:5(4). pii: e01514-16.

doi: 10.1128/genomeA.01514-16.

PMID: 28126942

Draft Genome Sequences of 43 Lactobacillus Strains from the Species L. curvatus, L. fermentum, L. paracasei, L. plantarum, L. rhamnosus, and L. sakei, Isolated from Food Products.

Inglin RC, Meile L, Stevens MJA

Genome Announc. 2017 Jul 27;5(30). pii: e00632-17. PMID: 28751390 .

Prevalence of Vitamin D Deficiency and Its Associations with Skin Color in Pregnant Women in the First Trimester in a Sample from Switzerland.

Richard A, Rohrmann S, Quack Lotscher KC.

Nutrients. 2017 Mar 10;9(3). pii: E260.

doi: $10.3390 /$ nu 9030260

PMID: 28287422

\section{6}

Barriers to healthy eating in Switzerland: A nationwide study.

de Mestral C, Stringhini S, Marques-Vidal P.

Clin Nutr. 2016 Dec;35(6):1490-1498. doi: $10.1016 / \mathrm{j}$ clnu.2016.04.004. Epub 2016 Apr 7.

PMID: 27091772

Tracing and inhibiting growth of Staphylococcus aureus in barbecue cheese production after product recall.

J Dairy Sci. 2016 May;99(5):3345-

doi : 10.3168/jds. 2015-10689. Epub 2016 Mar 9. PMID: 26971157
RE-AIM evaluation of a one-year trial of a combined edlower salt inta Sequence Variability in Staphylococcal Enterotoxin Genes seb, sec, and sed.

Johler S, Sihto HM, Macori G, Stephan R. Toxins (Basel). 2016 Jun 1;8(6). pii: E169. doi: $10.3390 /$ toxins 80601

An (un)healthy poster: When environmental cues affect consumers' food choices at vending machines.

Appetite. 2016 Jan 1;96:368-374

doi: 10.1016/j.appet.2015.09.034. Epub 2015 Oct 22. PMID: 26431685

Mechanically Enhanced Liquid Interfaces at Human Body Temperature Using Thermosensitive Methylated Nanocrystalline Cellulose.

Pester S, Adamcik J, Mezzenga R, Langmuir 2016 Feb $9 ; 32$

doi: 10.1021/acs.langmuir.5b04231. Epub 2016 Jan 27. PMID: 26779953

Risk factors for oral antimicrobial consumption in Swiss fattening pig farms - a case-control study.

Arnold C, Schapbach-Regula G, Hirsiger P, Malik J, Scheer P, Sidler X, Spring P, Peter-Egli J, Harisberger M.

doi: 10.1186/s40813-016-0024-3, eCollection 2016.

28405431

Fusarium and mycotoxin spectra in Swiss barley are affected by various cropping techniques.

Schöneberg T, Martin C, Wettstein FE, Bucheli TD, Mascher F, Bertossa M, Musa T, Keller B, Vogelgsang S. Food Addit Contam Part A Chem Anal Control Expo Ris PMID: 2749181

Blocking Gastric Lipase Adsorption and Displacement Processes with Viscoelastic Biopolymer Adsorption LayScheuble N, Lussi M, Geue T, Carrière F, Fischer P. Biomacromolecules. 2016 Oct 10;17(10):3328-3337. Epub 2016 Sep 27.
PMID: 27635994

Emulsion Stability Modulates Gastric Secretion and Its Mixing with Emulsified Fat in Healthy Adults in a RandLi Desnetic Resonance Imaging Study.

er HL, Curcic J, Kozerke S, Steingoetter A. Oct;146(10):2158-2164. Epub 2016 Sep 7 
The visualisation and quantification of human gastrointestinal fat distribution with MRI: a randomised study in healthy subjects.

Liu D, Parker HL, Curcic J, Schwizer W, Fried M, Kozerke S, Steingoetter A.

Br J Nutr. 2016 Mar 14;115(5) :903-12.

doi: 10.1017/S0007114515005188. Epub 2016 Jan 19. PMID: 26782705

Scanning-SAXS of microfluidic flows: nanostructural mapping of soft matter.

, $P$, Liebi M.

Lab Chip. 2016 Oct $5 ; 16(20): 4028-4035$

PMID: 27713983

\section{5}

Further evidence for staphylococcal food poisoning outbreaks caused by egc-encoded enterotoxins. Toxins (Basel). 2015 Mar $20 ; 7$

;7(3):997-1004

doi: $10.3390 /$ toxins7030997.

PMID: 25802973

Outbreak of staphylococcal food poisoning among children and staff at a Swiss boarding school due to soft cheese made from raw milk.

Jummerion J Dairy Sci. 2015 May:98(5):294.

jds.2014-9123. Epub 2015 Feb 26

Complete and Assembled Genome Sequence of Staphylococcus aureus RKI4, a Food-Poisoning Strain Exhibiting a Novel S. aureus Pathogenicity Island Carrying seb.

Stevens MJ, Stephan R, Johler S.

Gii: e00769-15.

PMID: 26139727

Temporal expression of the staphylococcal enterotoxin

gene under $\mathrm{NaCl}$ stress conditions.

Sihto HM, Tasara T, Stephan R, Johler S.

FEMS Microbiol Lett. 2015 Mar,362(6). pii. fnv024.

doi: 10.1093/femsle/fnv024. Epub 2015 Feb 16.

Quantity and quality of food losses along the Swiss potato supply chain: Stepwise investigation and the influence Willersinn $C$, Mack $\mathrm{C}$, losses.

Waste Manag. 2015 Dec:46:120, Keiser A, Siegrist M.

doi: 10.1016/j.wasman.2015.08.033. Epub 2015 Sep 2. PMID: 26341828
Imaging gastric structuring of lipid emulsions and its effect on gastrointestinal function: a randomized trial in healthy subjects.

Steingoetter A, Radovic T, Buetikofer S, Curcic J, Menne D, Fried M, Schwizer W, Wooster TJ.

doi: 10.3945/ajcn.114.100263. Epub 2015 Feb 25.

PMID: 25833970

New concepts to fight oxidative stress: nanosized three-dimensional supramolecular antioxidant assemblies Expert Opin Drug Deliv . 2015 12 (9) $: 1527-45$.

doi: 10.1517/17425247.2015.1036738. Epub 2015 Apr 16. Review.

\section{PMID: 25882382}

High-throughput screening assays for antibacterial and antifungal activities of Lactobacillus species.

.

doi: 10.1016/j.mimet.2015.04.011. Epub 2015 Apr 30.

\section{4}

Validation of reference genes for normalization of qPCR mRNA expression levels in Staphylococcus aureus exposed to osmotic and lactic acid stress conditions enSihto HM Tas T S Tephan R, Johler S. FEMS Mich The doi: 10.1111/1574-6968.12491. Epub 2014 Jun 19 PMID: 24893820

Completed egoism and intended altruism boost healthy food choices.

Weibel C, Messner C, Brügger A.

Appetite. 2014 Jun, $77: 3845$

.appet.2014.02 010. Epub 2014 Feb 24

Inheritance of porcine receptors for enterotoxigenic Escherichia coli with fimbriae F4ad and their relation to other F4 receptors.

Bratus A, Vögeli P, Neuenschwander S.

Animal. 2014 Jun;8(6):859-66.

doi: 10.1017/S1751731114000779. Epub 2014 Apr 11

"Active surfaces" formed by immobilization of enzymes on solid-supported polymer membranes.

C, Kowal J, Darjan A, Meier W, Palivan CG.

Langmuir 2014 Oct $7 ; 30(39): 11660-9$.

02841p. Epub 2014 Sep 23. 
Annexe 2

Members of the steering committee
Fred Paccaud, UniSanté, Center for general medicine and public health; Faculty of biology and medicine University of Lausanne (President)

Stefania Boccia, Institute of Hygiene, Department of Public Health, Faculty of Medicine, Università Cattolica del Sacro Cuore of Rome, Italy

Paolo Boffetta, Institute for Translational Medicine, Icahn School of Medicine at Mount Sinai, NY, USA

Alan Dangour, Centre on Climate Change and Planetary Health, London School of Hygiene \& Tropical Medicine, UK

Lynn Frewer, School of Natural and Environmental Sciences, University of Newcastle, UK

Dietrich Knorr, Institute of Food Technology and Food

Barbara Redlingshöfer, AgroParisTech, UMR SADAPT, INRA, Paris, FR

Greg Thoma, Ralph E. Martin Department of Chemical Engineering, University of Arkansas, USA

Bruce Traill, Agricultural \& Food Economics, University of Reading, UK

Marjory Hunt, SNSF, Berne, CH (Programme Manager)

Xavier Pilloud, VIRTÙ Public Affairs AG, Berne, CH (Head of Knowledge Transfer)

Stefanie Hellweg, Institute of Environmenta Engineering, ETHZ, Zürich, CH (SNSF Research Counci Delegate)

Michael Beer, Federal Office of Public Health, Berne, $\mathrm{CH}$ (representative of the Federal Administration)

Markus Lötscher, Federal Office of Agriculture, Berne, $\mathrm{CH}$ (representative of the Federal Administration)

Barbara Keller, CTI-KTI (now Innosuisse), Bern, CH (representative of the Commission for Technology and Innovation) 
June 2020

Publisher
National Research Programme NRP 69

National Research
Swiss National

Science Foundation (SNSF)
Wildhainweg 3

Wildhainweg
P.O. Box
CH -3001 Berne

Project management

Layout/graphics
Karakter Graphic Design

Pictures
Mélanie Rouiller 